\title{
Akt: A Double-Edged Sword in Cell Proliferation and Genome Stability
}

\author{
Naihan Xu, ${ }^{1}$ Yuanzhi Lao, ${ }^{2}$ Yaou Zhang, ${ }^{1}$ and David A. Gillespie ${ }^{3,4}$ \\ ${ }^{1}$ Division of Life Science, Graduate School at Shenzhen, Tsinghua University, Shenzhen 518055, China \\ ${ }^{2}$ School of Pharmacy, Shanghai University of Traditional Chinese Medicine, Cai Lun Lu 1200, Shanghai 201203, China \\ ${ }^{3}$ The Beatson Institute for Cancer Research, Garscube Estate, Switchback Road, Glasgow G61 1BD, Scotland, UK \\ ${ }^{4}$ College of Medical, Veterinary and Life Sciences, University of Glasgow, Glasgow G12 8QQ, UK \\ Correspondence should be addressed to Naihan Xu, xu.naihan@sz.tsinghua.edu.cn and \\ David A. Gillespie, d.gillespie@beatson.gla.ac.uk
}

Received 26 October 2011; Accepted 29 December 2011

Academic Editor: Richard T. Penson

Copyright ( 2012 Naihan Xu et al. This is an open access article distributed under the Creative Commons Attribution License, which permits unrestricted use, distribution, and reproduction in any medium, provided the original work is properly cited.

The Akt family of serine/threonine protein kinases are key regulators of multiple aspects of cell behaviour, including proliferation, survival, metabolism, and tumorigenesis. Growth-factor-activated Akt signalling promotes progression through normal, unperturbed cell cycles by acting on diverse downstream factors involved in controlling the G1/S and G2/M transitions. Remarkably, several recent studies have also implicated Akt in modulating DNA damage responses and genome stability. High Akt activity can suppress ATR/Chk1 signalling and homologous recombination repair (HRR) via direct phosphorylation of Chk1 or TopBP1 or, indirectly, by inhibiting recruitment of double-strand break (DSB) resection factors, such as RPA, Brca1, and Rad51, to sites of damage. Loss of checkpoint and/or HRR proficiency is therefore a potential cause of genomic instability in tumor cells with high Akt. Conversely, Akt is activated by DNA double-strand breaks (DSBs) in a DNA-PK- or ATM/ATR-dependent manner and in some circumstances can contribute to radioresistance by stimulating DNA repair by nonhomologous end joining (NHEJ). Akt therefore modifies both the response to and repair of genotoxic damage in complex ways that are likely to have important consequences for the therapy of tumors with deregulation of the PI3K-Akt-PTEN pathway.

\section{Akt Family Kinases}

As one of the most versatile kinase families, Akt (also known as $\mathrm{PKB}$ ) serine-threonine kinases function as critical regulators of cell survival, proliferation, metabolism, and migration. Deregulation of Akt kinases is frequently associated with human diseases such as cancer and diabetes. Three isoforms of Akt have been identified in mammals: Akt1, Akt2, and Akt3 [1-3]. The Akt isoforms share approximately $80 \%$ amino acid identity and are thought to have similar primary substrate specificity [4]. They are widely expressed in various tissues; Akt1 is most abundant in brain, heart, and lung, whereas Akt2 is predominantly expressed in skeletal muscle and embryonic brown fat. Akt3 is mainly expressed in kidney, brain, and embryonic heart [3, 5-7]. Findings from Akt isoform-specific knockout mice suggest that Akt family kinases are likely to have distinct biological functions in vivo. Thus, Akt1 knockout mice are smaller than littermate controls and show increased rates of apoptosis in some tissues, reflecting the role of Akt1 in cell survival $[8,9]$. By contrast, Akt2 null mice develop type 2 diabetes and impaired glucose utilization, suggesting that Akt2 function is more specific for the insulin receptor signaling pathway $[10,11]$. The precise role of Akt3 is less clear, however, mice lacking Akt3 display impaired brain development [12]

All three Akt isoforms share a conserved N-terminal pleckstrin homology $(\mathrm{PH})$ domain, a central kinase domain, and a C-terminal regulatory domain which contains the hydrophobic motif, a characteristic of the cAMP-dependent protein kinase A/protein kinase G/protein C (AGC) superfamily of protein kinases [13]. In response to various growth factors and cytokines, Akt activity is modulated downstream of phosphatidylinositol 3 (PI3) kinase via a multistep process. Activated PI3 kinase localizes to the cytoplasmic 
face of the plasma membrane, where it converts PIP2 (phosphatidylinositol 4,5-bisphosphate) to PIP3 (phosphatidylinositol 3,4,5-trisphosphate). PIP3 functions to activate downstream signaling components by recruiting proteins containing $\mathrm{PH}$ domains to the plasma membrane, such as Akt and PDK1 kinases [14-17]. Once recruited to the plasma membrane, Akt is activated by site-specific phosphorylation at residues Thr308 and Ser473. PDK1 phosphorylates Thr308 within the activation T-loop of the catalytic domain [18]. Ser473 within the carboxyl terminal hydrophobic domain can be phosphorylated by mammalian target of rapamycin complex 2 (mTORC2) [19]; however, other molecules, including integrin-linked kinase (ILK) and mitogen-activated protein kinase-activated protein linase-2 (MAPKAPK2), have also been reported to phosphorylate this residue $[20,21]$.

Once activated, Akt phosphorylates numerous substrates throughout the cell to regulate multiple cellular events and processes. Akt can also be activated in a PI3K-independent manner. For example, cAMP elevating agents have been shown to activate Akt through PKA [22, 23], whilst $\mathrm{Ca}^{2+} /$ calmodulin-dependent kinase can directly phosphorylate and activate Akt in vitro $[24,25]$. Several nonkinase interactors such as Hsp90, Hsp27, Tcl1, Geb10, and Ft1 have also been described to positively regulate Akt catalytic activity [13].

Negative regulation of PI3K/Akt pathways is mainly accomplished by PTEN (phosphatase and tensin homologue deleted on chromosome 10). PTEN was originally identified as a tumor-suppressor gene and is frequently mutated in a wide variety of solid tumors, including endometrial, breast, prostate carcinomas, and glioblastomas [26-28]. As a dual lipid and protein phosphatase, the primary physiological target of PTEN is considered to be the PI3K/Akt pathway [2931]. PTEN specifically catalyses dephosphorylation of the $3^{\prime}$ phosphate of the inositol ring in PIP3, resulting in the biphosphate product PIP2 and inhibition of Akt activity [32]. Inactivating mutations or loss of PTEN expression leads to a permanent increase in the basal level of PI3K/Akt signaling, generally resulting in increased cell proliferation and resistance to apoptosis.

Recently, a family of novel protein phosphatases, namely, PHLPP (PH domain and leucine-rich repeat protein phosphatase), have been identified as important regulators of Akt kinases and protein kinase C (PKC) [33-35]. Two isoforms, PHLPP1 and PHLPP2, directly dephosphorylate Ser473 and therefore inactivate Akt. It has been shown that PHLPP differentially terminates Akt signaling by regulating distinct Akt isoforms. PHLPP2 dephosphorylates Akt1 and Akt3, whereas PHLPP1 is specific for Akt2 and Akt3 [35]. Several lines of evidence suggest that PHLPP functions as a tumor suppressor. PHLPP expression is commonly lost in cancer, including colon, breast, ovarian, Wilms tumors, and prostate cancer $[33,36,37]$. Overexpression of PHLPP1 in a glioblastoma cell line inhibits tumor growth in xenografted nude mice [34], and decreased expression of PHLPP has been linked to the metastatic potential of $21 \mathrm{~T}$ breast cancer cells [38]. Codeletion of PHLPP1 and PTEN is strongly associated with metastatic prostate cancer and tightly correlated to deletion of 553 and PHLPP1, suggesting the role of PHLPP as a prostate tumor suppressor [37].

\section{Role of Akt in Normal Cell Cycle Progression}

Remarkable progress has been made in determining how Akt promotes cell cycle progression. Activated Akt kinase modulates the function of numerous substrates related to cell cycle progression at the G1/S and G2/M transitions, either by direct phosphorylation of the target proteins themselves or, indirectly, by regulating protein expression levels. These are discussed in detail in the following and depicted in Figure 1.

2.1. Mechanisms of Akt Regulation of G1/S Progression. Addition of mitogens to quiescent (G0) mammalian cells rapidly triggers a number of biochemical signalling cascades, including the PI3K/Akt pathway, to promote cell growth through two key enzymes mTOR and p70S6K [39-42]. As depicted in Figure 1, growth-factor-mediated Akt activation increases the transcription of c-Myc, a strong promoter of cell cycle progression, causing cells to exit G0 both by inducing the expression of D-type cyclins and suppressing the expression of multiple negative cell cycle regulators such as $\mathrm{p} 21^{\mathrm{Cip} 1}$, p $27^{\text {Kip } 1}$, and $\mathrm{p} 15^{\text {INK4b }}[43,44]$. Akt also controls the stability of c-Myc and cyclin D1 indirectly via its downstream substrate, GSK-3 $\beta$. GSK- $3 \beta$ phosphorylates c-Myc at Thr58, which appears to be required for ubiquitin-dependent proteolysis $[45,46]$. Cyclin D1 is phosphorylated by GSK-3 $\beta$ at Thr286, a modification that induces nuclear-cytoplasmic translocation of cyclin D1 leading to ubiquitin-dependent proteolysis in the cytoplasm $[47,48]$. Furthermore, PI3K/Akt is also necessary and sufficient to induce E2F transcriptional activity in $\mathrm{T}$ cells through phosphorylating and deactivating $\mathrm{Rb}[49]$.

Another important function of Akt in G1/S progression is positive regulation of mid- and late-G1-phase cyclin/Cdk activity via phosphorylation and inactivation of Cdk inhibitors, including $\mathrm{p} 21^{\mathrm{Cip} 1}$ and $\mathrm{p} 27^{\mathrm{Kip} 1}$. Akt phosphorylates p21 ${ }^{\mathrm{Cipl}}$ at Thr145, within its nuclear localization sequence (NLS), to recruit $\mathrm{p}_{21}{ }^{\mathrm{Cip} 1}$ from the nucleus to the cytoplasm and suppress its inhibitory effect on cell cycle progression [50]. Akt-mediated T145 phosphorylation also prevents p21 ${ }^{\text {Cipl }}$ forming a complex with PCNA to inhibit DNA replication and decreases its binding to Cdk2/Cdk4 and attenuates its Cdk2 inhibitory activity [51]. In addition to Thr145, Ser146 is also phosphorylated by Akt, a modification that significantly increases $\mathrm{p} 21^{\mathrm{Cip} 1}$ protein stability and protects cells from taxol-induced apoptosis [52]. Importantly, p21 Cip1 protein induced by Akt does not inhibit cyclin E-Cdk2 but rather promotes the assembly and activation of cyclin D1Cdk4 complex, which controls G1 to S phase progression and enhances cell cycling [52]. p21 ${ }^{\mathrm{Cip} 1}$ elevation in tumors correlates with enhanced survival and chemoresistance [53], indicating that stabilization of $\mathrm{p}^{2} 1^{\mathrm{Cip} 1}$ by Akt would be beneficial for tumor growth.

As with $\mathrm{p} 21^{\mathrm{Cip}}$, the expression, localization, and protein stability of $\mathrm{p} 27^{\mathrm{Kip} 1}$, are controlled by Akt-dependent phosphorylation. Akt is known to downregulate p27 Kipl 


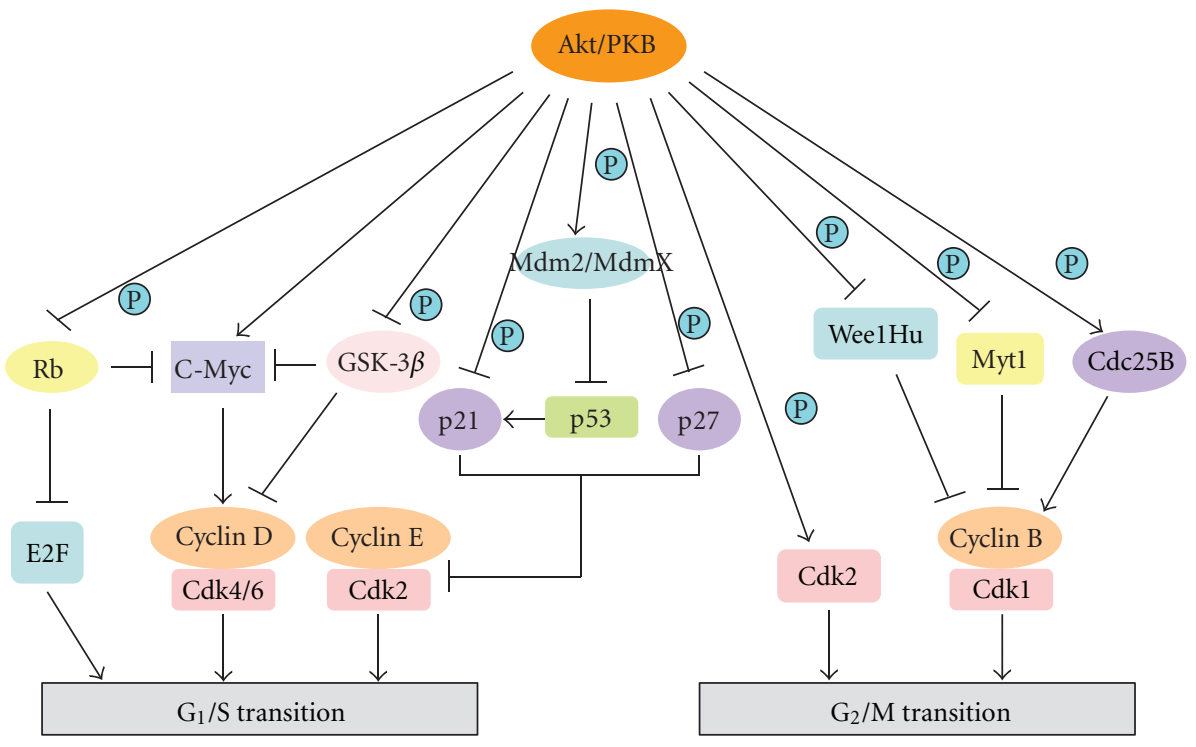

FIGURE 1: Role of Akt in normal cell cycle progression. Activated Akt kinase modulates the function of numerous proteins involved in cell cycle progression at the G1/S and G2/M transitions, either by direct phosphorylation of the target proteins themselves, or indirectly, by regulating protein expression levels. Please see text for additional explanation.

transcription by phosphorylation-dependent inhibition of the Forkhead family of transcription factors [54]. Akt directly binds to and phosphorylates $\mathrm{p} 27^{\mathrm{Kip} 1}$ at three residues, Ser10, Thr187, and Thr198 [55-58]. Ser10 phosphorylation could increase the nuclear export of $\mathrm{p} 27^{\mathrm{Kip} 1}$ through binding to CRM1, but it is not sufficient to promote the cytoplasmic localization of $\mathrm{p} 27^{\mathrm{Kip} 1}$ because an S10D mutant remains in the nucleus in G0/G1 cells [59]. Thr157 is within the nuclear localization sequence (NLS), and phosphorylation by Akt favours cytoplasmic accumulation of p27 $7^{\mathrm{Kip} 1}[55-57,60]$. When forced to localize to the cytoplasm, p2 $7^{\mathrm{Kip} 1}$ is less efficient in binding and inhibiting nuclear cyclin E-Cdk2 kinase activity and thus halting cell cycle progression [5557]. Phosphorylation of C-terminal Thr198 by Akt promotes 14-3-3 binding and cytoplasmic localization of p2 $7^{\text {Kip } 1}$ [58]. Remarkably, cytoplasmic mislocalization of $\mathrm{p} 27^{\mathrm{Kip} 1}$ has been observed in various human tumors [61, 62]. In up to $40 \%$ of primary human breast cancers, cytoplasmic p $27^{\text {Kip } 1}$ correlates with Akt activation, indicating that Akt-mediated cytoplasmic mislocalization of $\mathrm{p} 27^{\mathrm{Kip} 1}$ may be critical in the development of human cancers [55].

Interestingly, recent studies revealed that the protein stability of p $27^{\mathrm{Kip} 1}$ is controlled by Akt-dependent phosphorylation of Skp2 $[63,64]$. Skp2 is a key component of SCF (Skp1/Cul-1/F-box) E3 ubiquitin ligase; it binds to p27 Kip1 and targets it for ubiquitination and degradation [65-68]. Akt interacts with and directly phosphorylates Skp2 at Ser72, which triggers SCF complex formation and E3 ligase activity [63]. In addition, phosphorylation by Akt promotes the cytoplasmic localization of Skp2 and protects Skp2 from APC-Cdh1-mediated degradation [64]. High levels of active Akt correlates with the cytosolic accumulation of Skp2 in aggressive breast and prostate cancer patients, providing a rationale to develop specific Akt inhibitors as efficient anticancer drugs [64].

At the end of $G_{1}$ phase, a series of safeguards ensure that the DNA is intact and the cell is ready to initiate DNA replication. DNA damage and other stresses can activate the tumor suppressor p53, which binds to DNA and up-regulates the expression of several genes involved in cell cycle control, DNA repair, senescence, angiogenesis, and apoptosis [69, 70]. In normal cells p53 is maintained at very low levels, and $\mathrm{Mdm} 2$ targets $\mathrm{p} 53$ for ubiquitination and allows export of p53 from the nucleus to the cytoplasm where proteolysis takes place $[71,72]$. In response to growth factor stimulation, active Akt binds to and phosphorylates Mdm2 at Ser166 and Ser186 to enhance protein stability and facilitate the function of Mdm2 to promote p53 ubiquitination [73, 74]. Akt phosphorylation of $\mathrm{Mdm} 2$ is also necessary for the translocation of Mdm2 from the cytoplasm to the nucleus. Dominant-negative Akt inhibits nuclear entry of Mdm2, thus increasing the cellular level of p53 and transcriptional activity [75]. A close homologue of $\mathrm{Mdm} 2, \mathrm{MdmX}$, has also been shown to be an Akt target. Unlike Mdm2, MdmX does not possess E3 ubiquitin ligase activity; however, it binds to and stabilizes Mdm2. The heterocomplex of Mdm2-MdmX is more efficient for $\mathrm{p} 53$ ubiquitination [76, 77]. Akt also phosphorylates MdmX at Ser367, which generates a 14-3-3 binding site and leads to the stabilization of the Mdm2-MdmX complex [78]. Thus, oncogenic Akt is able to functionally inactivate $\mathrm{p} 53$ by regulating $\mathrm{Mdm} 2$ and MdmX stability.

2.2. Mechanisms of Akt Regulation of G2/M Progression. It has been reported previously that Akt activity is high in the G2/M phase of the cell cycle in epithelial cells 


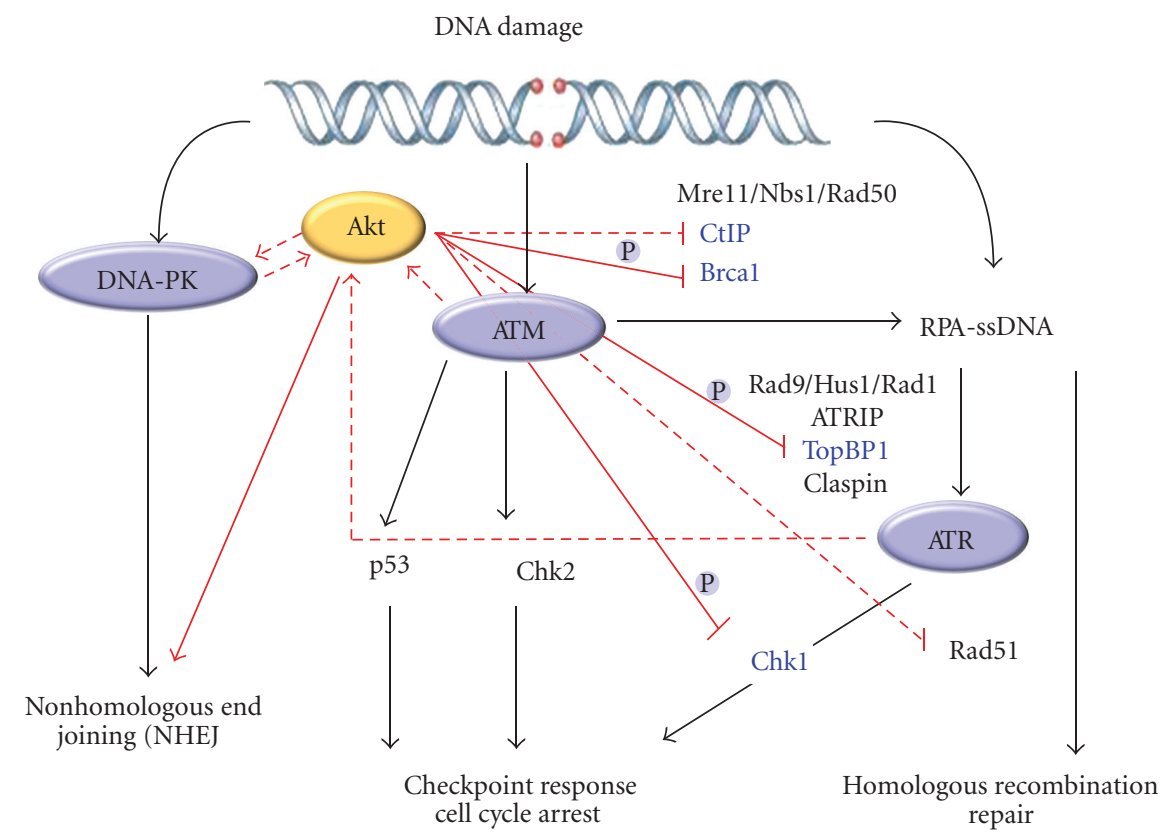

FIGURE 2: Crosstalk between Akt and DNA damage signalling pathways. Akt can be activated in response to DNA damage through the action of the PI3 kinase-like kinases (PIKKs) ATM, ATR, and DNA-PK. Conversely, active Akt can promote DNA repair via NHEJ and inhibit checkpoint signalling and repair via recombination through multiple mechanisms and targets. Please see text for additional explanation.

[79]. Akt activity protects cells from apoptosis during the G2/M transition and is necessary for efficient entry to mitosis during unperturbed cell cycles $[79,80]$. As shown in Figure 1, Akt regulates the G2/M transition through direct phosphorylation of both Cdk1 activators and inhibitors, suggesting that the PI3K/AKT pathway could function to promote mitosis [81, 82].

As one of the three human members of Cdc25 family of dual-specificity phosphatases, Cdc25B plays an important role in the control of the activity of Cdk1/cyclin B [83]. The function of Cdc25B is tightly linked to its intracellular localization [84]. During the G2/M transition, Cdc25B shuttles between the nucleus and the cytoplasm as a result of the opposing actions of the nuclear localization (NLS) and nuclear export signals (NES) in association with 14-3-3 family members [81]. Akt-mediated Ser353 phosphorylation regulates the cytoplasmic accumulation of $\mathrm{Cdc} 25 \mathrm{~B}$ and contributes to mitotic entry by promoting its inactivation and access to specific substrates [82]. The Cdk1 inhibitor Wee1Hu (also known as Wee1A) is an Akt substrate in mammalian cells [85]. Akt binds to and phosphorylates Wee1Hu at Ser642 within its C-terminal catalytic domain during late $S$ and G2 phase. Ser642 phosphorylation does not affect the kinase activity; however, it promotes cytoplasmic localization of Wee1Hu through binding to $14-3-3 \theta$ [85]. As a result, coexpression of Akt together with Wee1Hu and 14-3-30 overcomes the G2/M arrest induced by Wee1Hu alone [85]. Another Cdk1 inhibitor Myt1 has also been shown to be a substrate for Akt in oocytes from the starfish Asterina pectinifera [86]. Akt phosphorylates Myt1 at Ser75 and severely reduces Myt1-mediated Tyr15 Cdk1 phosphorylation resulting in the activation of cyclin B-associated Cdk1 kinase activity [86]. Microinjection of nonphosphorylated mutant Myt1 completely abolishes 1-MdAde-induced meiotic reinitiation [86]. Thus, the direct phosphorylation of Myt1 by Akt reverses the balance between Myt1 and Cdc25 activities and initiates the activation of cyclin B-Cdc2 to cause meiotic G2/M-phase transition.

A recent study suggests that Akt can also regulate the progression of $\mathrm{S}$ to $\mathrm{G} 2$ phase via phosphorylation of Cdk2. There is a transient nucleocytoplasmic shuttling of Akt during late $S$ and G2 phases [87]. Nuclear Akt phosphorylates Cdk2 at Thr39 which causes temporary cytoplasmic localization of cyclin A/Cdk2 complex. The cytoplasmic redistribution of Cdk2 is required for cell cycle progression from $S$ to $G 2 / M$ phase, as nonphosphorylated Cdk2 T39A mutant severely affects cell cycle progression. In addition to its role in cell cycle progression, Akt-mediated phosphorylation and cytoplasmic translocation of Cdk2 is also important for apoptosis induced by stresses such as methotrexate and docetaxel [87]. Phosphorylated Cdk2 is sequestered in the cytoplasm and directed to different cytoplasmic substrates including p53, ultimately leading to cell death $[87,88]$.

\section{Role of Akt in Genome Stability}

3.1. Akt Regulation in Response to DNA Damage. As depicted in Figure 2, Akt is activated not only by growth factors but also by DNA damage $[18,89]$. The PIKK family members ATM, ATR, and DNA-PK are involved in Akt activation in 
response to genotoxic stresses, which may provide a prosurvival signal by triggering cell cycle arrest or inhibiting apoptosis [90-93].

In vertebrates, ATM is recruited to and activated primarily at DNA double-strand breaks in conjunction with MRN (Mre11 : Rad50 : NBS1) complex. Once activated, ATM triggers the phosphorylation of multiple substrates at the site of damage, such as $\mathrm{H} 2 \mathrm{AX}$, Chk2, and tumor suppressor p53, leading to cell cycle arrest, DNA repair, or apoptosis. Mutation of the ATM-gene results in Ataxia telangiectasia (AT), a rare human disease characterized by growth retardation, severe immunodeficiency, insulin resistance, hypersensitivity to radiation, and predisposition to cancer [94]. Interestingly, Akt knockout mice show some similar phenotypic abnormalities to ATM-deficient mice, such as growth retardation, insulin resistance, hypersensitivity to gamma-irradiation, and immunodeficiency $[8,11,95]$, indicating that ATM and Akt may be involved in the same signalling transduction pathway. Viniegra et al. provide clear evidence that ATM acts as an upstream activator of Akt in response to insulin or $\gamma$ radiation [91]. Overexpression of exogenous ATM and Akt in Cos cells promotes Akt Ser473 phosphorylation by insulin or IR and the phosphorylation depends on the PI3Klike catalytic domain of ATM. Although ATM binds to Akt directly, there is no apparent direct phosphorylation of Akt Ser473 by ATM, suggesting that other intermediate proteins downstream of ATM may be involved in direct phosphorylation of Akt in response to insulin or IR. Interestingly, another study by Caporali et al. demonstrates that ATR, but not ATM, is required for Akt phosphorylation at Ser473 in response to temozolomide (TMZ), a therapeutic methylating agent [93]. siRNA-mediated knockdown of ATR but not ATM expression results in abrogation of TMZ-induced phosphorylation of Akt [93]. However, there is no clear evidence that ATR phosphorylates Akt directly in response to TMZ. It is possible that ATR mediates activation of another kinase to phosphorylate Akt.

It has been proposed that DNA-PK (DNA-dependent protein kinase) is also involved in Akt activation in response to DNA damage such as IR and doxorubicin [92]. This pathway is specific for DNA damage as DNA-PK is dispensable for Akt Ser473 phosphorylation upon insulin or growth-factor stimulation [92]. Interestingly, phosphorylated Akt forms nuclear foci and colocalizes with DNA-PK at double-strand DNA breaks and the interaction between Akt and DNA-PK is DNA damagedependent [92]. Akt1 knockout mice resemble the DNA-PK deficiency radiosensitivity phenotype, with attenuated $\mathrm{p} 21^{\mathrm{Cip} 1}$ expression and increased apoptosis in response to DNA damage, supporting the notion that DNAPK/Akt1 pathway has a marked impact on cell survival after DNA damage due to transcriptional regulation of $\mathrm{p} 21^{\text {Cip } 1}$ [92]. Beside Akt1, Akt2 and DNA-PK are also required for the stabilization of p53 in response to IR, which is mediated by the inactivation of GSK-3 [96]. The above results suggest a novel mechanism through which DNA-PK phosphorylates and activates Akt at the site of DNA double-strand breaks. This process triggers the induction of a transcriptional program that promotes cell survival in response to DNA damage. Whether DNA-PK directly phosphorylates Akt itself or acts through PDK1 and whether DNA-PK and Akt interact directly remain unclear $[97,98]$.

\subsection{Akt Modulates DNA Damage Checkpoint Signalling and} DNA Repair. Mounting evidence implicates the role of Akt in modulating checkpoint responses and DNA repair. Activation of Akt overcomes DNA-damage-induced G2 arrest and apoptosis in a p53-independent manner [80, 99-102]. Overexpression of a constitutive active form of Akt or loss of PTEN abrogates G2 cell cycle checkpoint and Chk1 activation upon exposure to genotoxic stresses [80]. In addition, Akt-mediated suppression of G2 arrest is associated with reduced recruitment of Chk2 to sites of DNA damage and inhibition of Chk2 activation in human glioblastoma cells [103]. The ability of Akt to suppress G2 arrest induced by disparate agents suggests that Akt has a broad ability to override this checkpoint regardless of the pathway by which the process is initiated [103].

As the most hazardous DNA lesions, DNA double-strand breaks (DSBs) can lead to genome rearrangements and cell death following exposure to genotoxic stresses. Two mechanisms are primarily involved in repair of DSBs: nonhomologous end joining (NHEJ) and homologous recombination repair (HRR) [104, 105]. NHEJ is evolutionarily conserved in all kingdoms of life and is the predominant DSB repair pathway throughout the cell cycle [106-108]. HRR is a more accurate repair mechanism but restricted to $S$ and G2 phases $[109,110]$. Numerous studies have shown that inhibition of Akt activity impairs DSB repair [111-115]. Specific Akt inhibitors or AKT1 siRNA markedly reduce radiationinvduced DNA-PKcs phosphorylation at T2609 and S2056, modifications required for activation of DNA-PKcs [116, 117]. Akt1 physically associates with DNA-PKcs, indicating that Akt1 may function as a signalling kinase relevant for DNA-PKcs activation and NHEJ repair [111-115]. It has been shown in malignant glioblastoma that EGFR/ERK/Akt signalling promotes $\gamma \mathrm{H} 2 \mathrm{AX}$ foci resolution and enhances both NHEJ and HR repair by modulating the localization, expression, and phosphorylation of DNA-PKcs, ATM, and Rad51. Inhibition of either Akt or MEK/ERK results in significant reduction of NHEJ [115]. These results strongly argue that both Akt and MEK/ERK signalling are critical effectors downstream of EGFR that modulate DNA repair and may contribute to radioresistance in malignant glioblastoma with deregulated EGFR/ERK/Akt signalling. Interestingly, recent studies show that DNA-PKcs acts as an upstream signal for Akt phosphorylation and activation in response to genotoxic stresses $[92,96,118]$, suggesting that Akt and DNA-PKcs are tightly coregulated in both checkpoint response and DNA repair.

The activation of HRR in S and G2 phases regulates the accurate repair of DNA lesions, but unregulated HRR could result in amplification of repeated genomic sequences and loss of heterozygosity $[119,120]$. In contrast to the positive role of Akt in modulating NHEJ repair, however, recent studies reveal that oncogenic Akt promotes genome instability by repressing HRR under pathologic circumstances. In breast cancer cell lines with high level of Akt1 activity, 


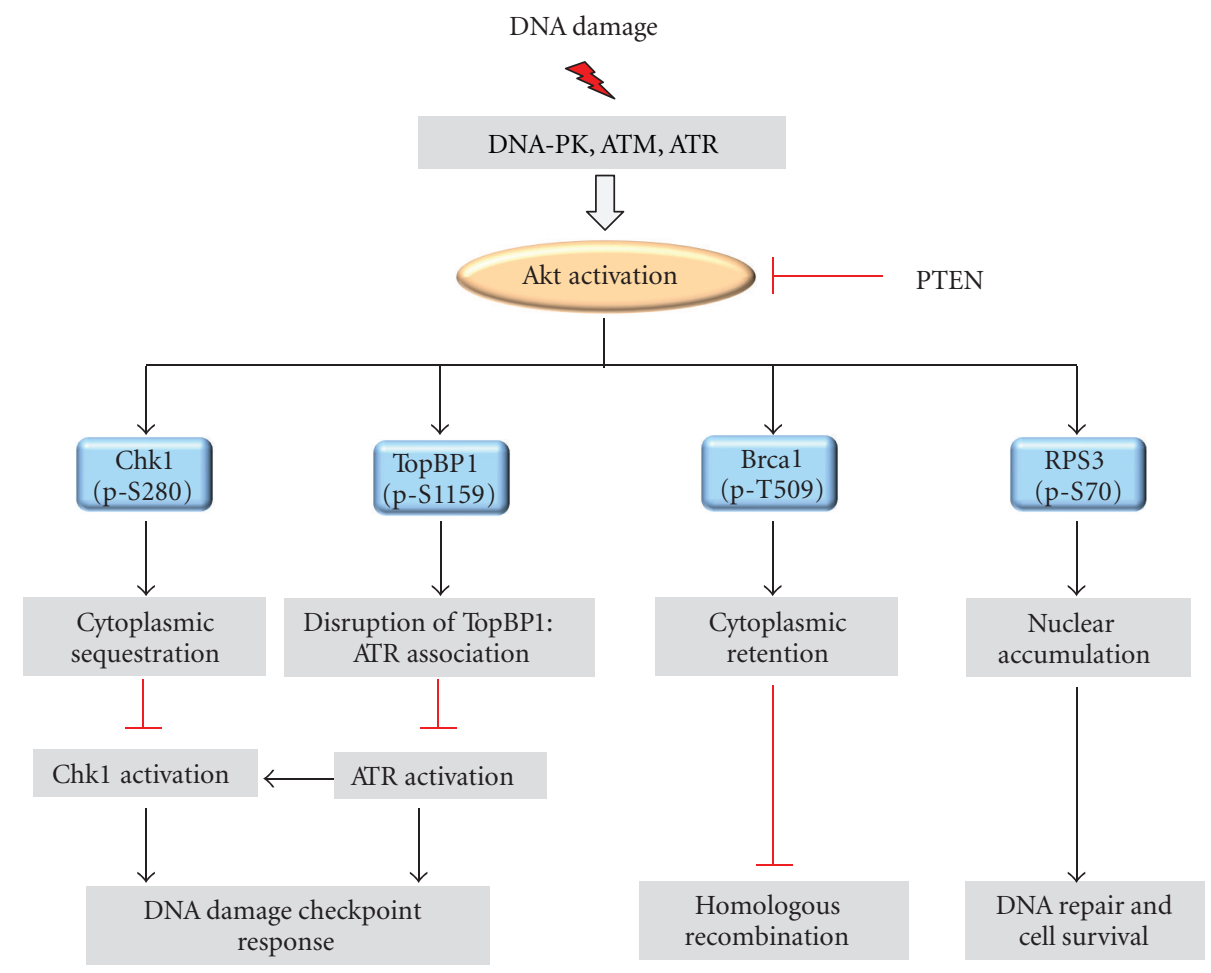

FIGURE 3: Molecular mechanisms and targets for Akt-mediated genomic instability. Akt can inhibit DNA repair, recombination, and checkpoint signalling by phosphorylating key regulatory proteins such as Chk1, TopBP1, Brca1, and RPS3 at specific sites. Please see text for additional explanation.

IR-induced Brcal and Rad51 foci formation and HRR are strongly impaired compared to cells with low Aktl activity [121]. Biopsies of sporadic breast cancer patients show strong correlation of Aktl activation with cytoplasmic Brcal and Rad51 localization [121]. In addition, active Akt1 induces supernumerary centrosomes and aneuploidy in hamster ovary cells [121].

The above results indicate a novel oncogenic function for Akt1 by producing genomic instability as a consequence of HRR repression, which may play an important function in the pathology of sporadic breast and ovarian cancer [121]. Recent studies by us also provide additional evidence and insight into mechanisms of genomic instability resulting from high level of active Akt due to loss of PTEN. In HCT116 cells ectopically expressing constitutively active Akt or lacking PTEN, both DNA-damage-induced RPA, CtIP and Rad51 foci formation and Chk1 activation are markedly suppressed. Conversely, inhibition of Akt by either selective chemical inhibitors or Akt siRNA restores DNA-damage-induced recruitment of RPA, CtIP, and Rad51 and Chk1 activation. Thus, the inhibitory effect of Akt on ATR-Chk1 signalling and HRR could be due to suppression of DNA damage processing [122].

3.3. Akt Targets Involved in DNA Damage Responses. Akt is thought to phosphorylate up to 100 substrates, some of which have been implicated in DNA damage checkpoint response and DNA repair. For instance, direct phosphorylation of cell cycle checkpoint kinase Chk1, TopBP1, Brcal, and
RPS3 by Akt is important for the activation of DNA damage signalling cascade [101, 123-125] (Figure 3). In addition, Akt activity is pivotal for the focal accumulation of key factors regulating DSB resection and DNA repair, including Rad51, Brca1, CtIP, and RPA [100, 121, 122, 126].

3.3.1. Chk1. As a key checkpoint kinase, Chk1 is activated by a wide range of genotoxic stresses. Activated Chk1 is essential for G2/M and replication checkpoint proficiency when DNA is damaged or replication is incomplete [127-130]. Chk1 is directly phosphorylated by Akt at Ser280, a modification that results in cytoplasmic sequestration $[79,99,101$, 123]. Ser 280 phosphorylated Chk 1 covalently associates with ubiquitin, ubiquitination of Chk1 does not alter the protein stability; however, it promotes enhanced cytoplasmic localization and inhibition of checkpoint function $[101,123]$. The increased cytoplasmic distribution of Chk1 is also seen in primary breast carcinomas tissues with elevated Akt phosphorylation and reduced PTEN level [101, 123]. Beside regulating the subcellular localization, Akt phosphorylation also inhibits the physical interaction between Chk1 and Claspin, which results in the inhibition of Chk1 activity and checkpoint proficiency [124]. By contrast, a recent study by Tonic et al. questions the significance of Chk1 S280 phosphorylation on the checkpoint function, since overexpression of exogenous Chk1 S280E mutant does not override radiationinduced G2 arrest [100]. This apparent discrepancy may be attributable to variable basal levels of active Akt in different cell lines. 
3.3.2. TopBP1. DNA topoisomerase 2-binding protein 1 (TopBP1) is an evolutionally conserved BRCT domain-rich protein that plays a critical role in DNA replication, DNA damage checkpoint responses, and transcriptional regulation [131]. In response to genotoxic stresses, TopBP1 colocalizes and interacts with ATR/ATRIP and promotes phosphorylation of Rad9 in the 9-1-1 (Rad9-Rad1-Hus1) clamp. The Cterminal ATR-activating domain of TopBP1 then stimulates the kinase activity of ATR $[132,133]$. Akt phosphorylates TopBP1 at Ser1159, a consensus sequence conserved in human, mouse, rat, and Xenopus. This modification induces oligomerization of TopBP1 through its seventh and eighth BRCT domains, and this self-association is crucial for its interaction with E2F1 and transcriptional repression [134]. Ser1159 phosphorylation may also prevent association of ATR with TopBP1 after DNA damage, thus inhibiting activation of ATR and G2/M checkpoint proficiency [124].

3.3.3. Brca1. The tumor suppressor and breast cancer susceptibility gene 1 (Brca1) has been shown to play an integral role in regulating DNA repair, cell cycle checkpoints, transcription, and maintenance of genomic stability. As one of the key players regulating DSB repair, Brcal forms nuclear foci in response to DNA damage where it colocalizes with Rad51 and facilitates Rad51 filament formation to initiate HR repair. It has been reported recently that oncogenic Akt 1 can repress HRR by inducing cytoplasmic retention of Brcal in human cancer cells $[100,121]$. Importantly, cytoplasmic retention of Brcal is strongly correlated with activated Akt1 in biopsies from sporadic breast cancer patients [121]. Although Akt is able to phosphorylate Thr509 of Brcal within the nuclear localization sequences (NLS), there is no direct evidence that Thr509 phosphorylation is required for cytoplasmic localization of Brcal [135-137]. One potential scenario could be that Thr509 phosphorylation prevents Brcal interacting with other proteins that localize to DNA damage foci. Conversely, Brcal could also regulate Akt pathway in a negative manner. Brcal interacts with phospho-Akt through Brcal-BRCT domains leading to its ubiquitination and degradation, thereby downregulating Akt signalling [138]. Thus, elucidation of the precise molecular functions of Brcal-Akt pathway will be particularly important to understand tumorigenesis of hereditary and sporadic breast cancer.

3.3.4. RPS3. Ribosomal protein S3 (RPS3) is a component of the $40 \mathrm{~S}$ ribosomal subunit which is required for ribosome biogenesis [139]. Apart from its ribosomal functions, RPS3 is also known as UV endonuclease III which participates in the cleavage of DNA lesions induced by UV irradiation. RPS3 has apurinic/apyrimidinic $(\mathrm{AP})^{2}$ endonuclease activity functioning in DNA repair at the $3^{\prime}$ of the AP sites after DNA damage [140-142]. A recent study by Lee et al. demonstrates that RPS3 is a physiological target of Akt and a novel mediator of neuronal apoptosis. Akt physically binds to and phosphorylates RPS3 at Thr70. Akt-dependent phosphorylation suppresses the proapoptotic function of RPS3 by governing its nuclear accumulation and enhancing its endonuclease activity [125]. It is conceivable that Akt promotes cell survival after DNA damage by regulating the DNA repair activity of RPS3 $[143,144]$. Manipulation of nuclear RPS3 and its Aktmediated phosphorylation might provide a new dimension for therapeutics of neurological diseases.

Several lines of evidence demonstrate the role of Akt in manipulating the subcellular localization or expression of the key factors regulating checkpoint response and DNA repair. Overexpression of constitutive active form of Akt or loss of PTEN disrupts the nuclear foci formation of DNA-PKcs, Rad51, Brca1, CtIP and RPA in response to DNA damage $[121,126]$. The cytoplasmic retention of Brcal and Rad51 also correlates with activated Akt1 in sporadic breast cancer tissues $[121,126]$. In addition, it has been proposed that Akt activity could regulate the expression of Mre11 through GSK3 $\beta / \beta$-catenin/LEF-1 pathway, which promotes the repair of radiation-induced DSBs in both CNE2 and HeLa cells [145]. The PI3K/Akt signalling pathway also acts together with MKK1/2-ERK1/2 to control Rad51 expression and protein stability in human non-small-cell lung cancer cells (NSCLCs) [146, 147].

\section{Implications for Cancer Development and Therapy}

Akt signaling is frequently activated in human cancers due to genetic and epigenetic alterations and has a role in neoplastic transformation [148-152]. Although Akt gene mutations are not widely reported, the amplification, overexpression, and activation of Akt occurs at high frequency in a number of human cancers [148, 150]. Alterations of Akt signalling in human cancer also result from mutations of the upstream PI3K kinase and PTEN. PTEN is one of the most frequently mutated genes, second only to p53 in human cancers $[30,153]$. Inactivation of PTEN is strongly correlated with the activation of Akt which in turn controls tumor cell proliferation. PTEN activity is lost by mutation, deletion, or promoter methylation silencing at high frequency in many primary and metastatic human cancers [154-156]. Many activating mutations have also been described in PI3KCA gene, upstream of Akt, which encodes one of the p110 $\alpha$ catalytic subunits of PI3K. PI3KCA mutations (E542K, E545K, H1047R) are frequently observed in human colon, gastric, breast, and lung cancers and glioblastoma. They are able to constitutively activate Akt and enhance its oncogenic activity [157-162].

The early stages of neoplasia are often associated with spontaneous genotoxic stresses resulting in DNA damage. If the damage is not repaired, DNA injury can result in mutation of tumor suppressor genes and activation of oncogenes, triggering uncontrolled cell proliferation and genome instability, the major cause of cancer. Inherited mutations that affect DNA repair genes are associated with human cancers $[105,163-166]$. However, the majority of cancers are sporadic; thus, understanding the mechanisms of tumorigenesis will be particularly important for cancer therapy. Recently, mounting evidence indicate that Akt signalling pathway plays a key role in modulating DNA damage response and genome stability in complex ways. 
TABLE 1: Akt inhibitors currently in clinical trials.

\begin{tabular}{|c|c|c|c|}
\hline Compound & Description & Phase & Tumor \\
\hline \multirow[t]{2}{*}{ MK-2206 } & \multirow[t]{2}{*}{$\begin{array}{l}\text { Allosteric kinase } \\
\text { inhibitor }\end{array}$} & I & $\begin{array}{l}\text { Metastatic solid tumors, non-small-cell lung cancer, advanced solid tumors, breast } \\
\text { cancer, leukemia, lymphoma, neoplasms malignant, kidney cancer, prostate cancer, } \\
\text { brain and central nervous system tumors, small intestine cancer }\end{array}$ \\
\hline & & II & $\begin{array}{l}\text { Ovarian cancer, fallopian tube and primary peritoneal cancer, leukemia, } \\
\text { lymphoma, colorectal neoplasms, breast cancer, esophageal cancer, gastric cancer, } \\
\text { endometrial cancer, prostate cancer, recurrent nasopharyngeal carcinoma, head and } \\
\text { neck cancer, kidney cancer, lung cancer, extrahepatic bile duct cancer, gallbladder } \\
\text { cancer, liver cancer }\end{array}$ \\
\hline \multirow[t]{3}{*}{ Perifosine } & \multirow[t]{3}{*}{$\begin{array}{l}\text { Lipid-based allosteric } \\
\text { kinase inhibitor }\end{array}$} & I & $\begin{array}{l}\text { Pediatric solid tumors, multiple myeloma, solid tumors, colon cancer, renal cancer, } \\
\text { ovarian cancer, neoplasms, brain and central nervous system tumors, leukemia, } \\
\text { lymphoma }\end{array}$ \\
\hline & & II & $\begin{array}{l}\text { Malignant gliomas, CNS, brain cancer, Waldenstrom's macroglobulinemia, } \\
\text { lymphomas, colon cancer, gastrointestinal stromal tumors, multiple myeloma, } \\
\text { chondrosarcomas, alveolar soft part sarcomas, kidney cancer, renal cell carcinoma, } \\
\text { leukemia, lymphoma, brain and central nervous system tumors, melanoma (skin), } \\
\text { endometrial cancer, sarcoma, prostate cancer, head and neck cancer, pancreatic } \\
\text { cancer, breast cancer }\end{array}$ \\
\hline & & III & Multiple myeloma, colorectal cancer \\
\hline GSK-2141795 & $\begin{array}{l}\text { ATP competitive } \\
\text { inhibitor }\end{array}$ & I & Ovarian cancer, solid tumors, and lymphoma \\
\hline \multirow[t]{2}{*}{ GSK-2110183 } & \multirow[t]{2}{*}{$\begin{array}{l}\text { ATP competitive } \\
\text { inhibitor }\end{array}$} & I & Multiple myeloma, hematologic malignancies \\
\hline & & II & Langerhans cell histiocytosis, hematologic malignancies \\
\hline RX-0201 & interfering RNA & II & Metastatic pancreatic cancer \\
\hline
\end{tabular}

Activated Akt may contribute to resistance to chemoor radiotherapy by stimulating NHEJ repair and promoting cancer cell survival. Several considerations argue that this may be the case. Firstly, the bulk of DSBs are repaired by NHEJ which is active throughout the cell cycle and DNAPK is required for NHEJ repair. It has been shown that Akt physically associates with DNA-PKcs and activates it by phosphorylation [113]. In addition, DNA-PKcs could activate Akt in response to genotoxic stresses [92]. Therefore this positive feedback loop could contribute to highly DNA repair proficiency and chemo- or radioresistance in some tumor cells with constitutive Akt activation. Secondly, oncogenic Akt may contribute to genomic instability via abrogation of cell cycle checkpoints, suppression of Chk1 activation and HRR, as well as induction of supernumerary centrosomes and aneuploidy. Taken together, activation of Akt pathway potentially contributes to tumorigenesis and tumor cell survival through multiple mechanisms. Future work will seek to evaluate the precise role of Akt in regulating these processes.

Over the past decade numerous studies have accumulated supporting the idea that inhibition of PI3K/Akt pathway leads to radiosensitization in glioblastoma and various carcinomas, including colon, bladder, prostate, head and neck, and cervix [167-175]. The combination of PI3K inhibitor and radiation causes an increase in apoptosis and a decrease in clonogenic survival, whereas expression of constitutively active Akt blocks apoptosis induced by radiation and prevents radiosensitization by PI3K inhibitor, indicating that activated Akt promotes cell survival through inhibition of IR-induced apoptosis [167-175]. Akt activity also promotes resistance to chemotherapy in breast cancer and ovarian cancer cell lines $[176,177]$. When combined with therapies commonly used in breast cancer treatment, the PI3K inhibitor enhances apoptosis caused by doxorubicin, trastuzumab, paclitaxel, etoposide, or tamoxifen, suggesting that inhibition of Akt in breast cancer patients may increase the efficacy of these therapies $[176,177]$. Loss of PTEN and the presence of active Akt are correlated with poor differentiation, lymph node involvement, distant metastasis, and late stage in NSCLC patients. Preclinical data suggest that modulation of Akt activity sensitizes cells to chemo- or radiotherapy [89, 178]. The combinations of drugs that modulate Akt activation with the therapeutic modalities used in NSCLC are thought to improve cancer treatment [150].

The PI3K/Akt/PTEN pathway therefore emerges as one of most promising targets of anticancer drugs in the immediate future. Currently, clinical trials with inhibitors of Akt in monotherapy or combination with other anticancer drugs are underway in cancer patients $[150,179]$ (Table 1). There are several promising candidate Akt inhibitors, such as lipidbased inhibitors that bind to the PH domain, ATP-competitive and noncompetitive small molecule inhibitors, and peptide-based inhibitors [150, 180, 181]. Perifosine (Keryx Biopharmaceuticals, New York, NY, US) is a lipid-based inhibitor which can inhibit the translocation of all Akt isoforms to the membrane by interacting with the $\mathrm{PH}$ domain $[182,183]$. In both preclinical and early clinical trials, perifosine displays antiproliferative effects in many tumor cell lines and sensitizes tumor cells to radiation and chemotherapy in vitro $[183,184]$. Phase II clinical trials with perifosine combined with radiotherapy, chemotherapy or other anticancer 
agents are ongoing $[150,180]$. MK-2206 (Merck and Co., Whitehouse Station, NJ, US) is an allosteric Akt inhibitor, which induces a conformational change in the Akt protein to inhibit both the activity and activation of the kinase and blocks signal transduction through the PTEN pathway $[185,186]$. Preclinical studies demonstrate that MK-2206 exerts more potent tumor inhibitory activities when in combination with other targeted therapies (erlotinib, lapatinib) or cytotoxic agents such as doxorubicin, docetaxel, and 5fluorouracil [187]. An oral phase I trial with MK-2206 in patients with advanced solid tumors was just completed $[179,188]$. Currently, over 10 enrolling phase II clinical trials with MK-2206 or combined with chemotherapy or targeted anticancer therapy are ongoing in multiple tumor types (http://clinicaltrials.gov/ct2/results?term=MK-2206). Other orally dosed ATP competitive Akt inhibitors undergoing phase I trials include GSK2141795 (GlaxoSmithKline, Brentford, UK) and GSK2110183 [189]. A potent ATP-competitive inhibitor GSK69069 shows strong efficacy in xenograft models from ovarian, prostate, and breast carcinoma cell lines [150]. It is currently in clinical development as an intravenous agent used in patients with solid tumors or haematological malignancies [189]. The search for small molecule inhibitor and peptide-based inhibitors is a new frontier in drug discovery. Akt antisense inhibitors are also being developed. RX-0201 represents an antisense oligonucleotide to Akt1. A phase II ongoing clinical trial is assessing the combination efficacy of RX-0201 and gemcitabine in metastatic pancreatic cancer $[179,190]$.

Beside that, inhibitors targeted upstream or downstream of Akt such as PI3K and mTOR are more advanced in their development than Akt inhibitors. Several PI3K and mTOR inhibitors are in preclinical and phase II clinical trials at present $[189,191]$. Regarding the complexity of PI3K/Akt/PTEN/mTOR signalling in different types of tumors, combinations of targeted therapeutics might be required for efficacy and safety for cancer treatment in the future.

\section{References}

[1] P. F. Jones, T. Jakubowicz, and B. A. Hemmings, "Molecular cloning of a second form of rac protein kinase," Cell Regulation, vol. 2, no. 12, pp. 1001-1009, 1991.

[2] J. Q. Cheng, A. K. Godwin, A. Bellacosa et al., "AKT2, a putative oncogene encoding a member of a subfamily of proteinserine/threonine kinases, is amplified in human ovarian carcinomas," Proceedings of the National Academy of Sciences of the United States of America, vol. 89, no. 19, pp. 9267-9271, 1992.

[3] D. Brodbeck, P. Cron, and B. A. Hemmings, "A human protein kinase $\mathrm{B} \gamma$ with regulatory phosphorylation sites in the activation loop and in the C-terminal hydrophobic domain," Journal of Biological Chemistry, vol. 274, no. 14, pp. 91339136, 1999.

[4] B. Vanhaesebroeck and D. R. Alessi, "The PI3K-PBK1 connection: more than just a road to PKB," Biochemical Journal, vol. 346, no. 3, pp. 561-576, 2000.

[5] P. J. Coffer and J. R. Woodgett, "Molecular cloning and characterisation of a novel putative protein-serine kinase related to the cAMP-dependent and protein kinase C families," European Journal of Biochemistry, vol. 201, no. 2, pp. 475-481, 1991.

[6] D. A. Altomare, K. Guo, J. Q. Cheng, G. Sonoda, K. Walsh, and J. R. Testa, "Cloning, chromosomal localization and expression analysis of the mouse Akt 2 oncogene," Oncogene, vol. 11, no. 6, pp. 1055-1060, 1995.

[7] D. A. Altomare, G. E. Lyons, Y. Mitsuuchi, J. Q. Cheng, and J. R. Testa, "Akt2 mRNA is highly expressed in embryonic brown fat and the AKT2 kinase is activated by insulin," Oncogene, vol. 16, no. 18, pp. 2407-2411, 1998.

[8] W. S. Chen, P. Z. Xu, K. Gottlob et al., "Growth retardation and increased apoptosis in mice with homozygous disruption of the akt1 gene," Genes and Development, vol. 15, no. 17, pp. 2203-2208, 2001.

[9] H. Cho, J. L. Thorvaldsen, Q. Chu, F. Feng, and M. J. Birnbaum, "Akt1/PKB $\alpha$ Is Required for Normal Growth but Dispensable for Maintenance of Glucose Homeostasis in Mice," Journal of Biological Chemistry, vol. 276, no. 42, pp. 3834938352, 2001.

[10] R. S. Garofalo, S. J. Orena, K. Rafidi et al., "Severe diabetes, age-dependent loss of adipose tissue, and mild growth deficiency in mice lacking Akt2/PKB $\beta$," Journal of Clinical Investigation, vol. 112, no. 2, pp. 197-208, 2003.

[11] H. Cho, J. Mu, J. K. Kim et al., "Insulin resistance and a diabetes mellitus-like syndrome in mice lacking the protein kinase Akt2 (PKB $\beta)$," Science, vol. 292, no. 5522, pp. 1728-1731, 2001.

[12] Z. Z. Yang, O. Tschopp, A. Baudry, B. Dümmler, D. Hynx, and B. A. Hemmings, "Physiological functions of protein kinase B/Akt," Biochemical Society Transactions, vol. 32, no. 2, pp. 350-354, 2004.

[13] G. Song, G. Ouyang, and S. Bao, "The activation of Akt/PKB signaling pathway and cell survival," Journal of Cellular and Molecular Medicine, vol. 9, no. 1, pp. 59-71, 2005.

[14] K. M. Ferguson, J. M. Kavran, V. G. Sankaran et al., "Structural basis for discrimination of 3-phosphoinositides by pleckstrin homology domains," Molecular Cell, vol. 6, no. 2, pp. 373-384, 2000.

[15] T. F. Franke, D. R. Kaplan, L. C. Cantley, and A. Toker, "Direct regulation of the Akt proto-oncogene product by phosphatidylinositol-3,4-bisphosphate," Science, vol. 275, no. 5300, pp. 665-668, 1997.

[16] D. Stokoe, L. R. Stephens, T. Copeland et al., "Dual role of phosphatidylinositol-3,4,5-trisphosphate in the activation of protein kinase B," Science, vol. 277, no. 5325, pp. 567-570, 1997.

[17] S. E. Lietzke, S. Bose, T. Cronin et al., "Structural basis of 3-phosphoinositide recognition by Pleckstrin homology domains," Molecular Cell, vol. 6, no. 2, pp. 385-394, 2000.

[18] D. R. Alessi, M. Andjelkovic, B. Caudwell et al., "Mechanism of activation of protein kinase B by insulin and IGF-1," EMBO Journal, vol. 15, no. 23, pp. 6541-6551, 1996.

[19] D. D. Sarbassov, D. A. Guertin, S. M. Ali, and D. M. Sabatini, "Phosphorylation and regulation of Akt/PKB by the rictormTOR complex," Science, vol. 307, no. 5712, pp. 1098-1101, 2005.

[20] M. Delcommenne, C. Tan, V. Gray, L. Rue, J. Woodgett, and S. Dedhar, "Phosphoinositide-3-OH kinase-dependent regulation of glycogen synthase kinase 3 and protein kinase $\mathrm{B} / \mathrm{AKT}$ by the integrin-linked kinase," Proceedings of the $\mathrm{Na}$ tional Academy of Sciences of the United States of America, vol. 95, no. 19, pp. 11211-11216, 1998. 
[21] A. Balendran, A. Casamayor, M. Deak et al., "PDK1 acquires PDK2 activity in the presence of a synthetic peptide derived from the carboxyl terminus of PRK2," Current Biology, vol. 9, no. 8, pp. 393-404, 1999.

[22] C. L. Sable, N. Filippa, B. Hemmings, and E. Van Obberghen, "cAMP stimulates protein kinase B in a Wortmannin-insensitive manner," FEBS Letters, vol. 409, no. 2, pp. 253-257, 1997.

[23] N. Filippa, C. L. Sable, C. Filloux, B. Hemmings, and E. Van Obberghen, "Mechanism of protein kinase B activation by cyclic AMP-dependent protein kinase," Molecular and Cellular Biology, vol. 19, no. 7, pp. 4989-5000, 1999.

[24] S. Yano, H. Tokumitsu, and T. R. Soderling, "Calcium promotes cell survival through CaM-K kinase activation of the protein-kinase-B pathway," Nature, vol. 396, no. 6711, pp. 584-587, 1998.

[25] M. J. Pérez-García, V. Ceña, Y. De Pablo, M. Llovera, J. X. Comella, and R. M. Soler, "Glial cell line-derived neurotrophic factor increases intracellular calcium concentration: role of calcium/calmodulin in the activation of the phosphatidylinositol 3-kinase pathway," Journal of Biological Chemistry, vol. 279, no. 7, pp. 6132-6142, 2004.

[26] M. P. Myers and N. K. Tonks, "PTEN: sometimes taking it off can be better than putting it on," American Journal of Human Genetics, vol. 61, no. 6, pp. 1234-1238, 1997.

[27] L. C. Cantley and B. G. Neel, "New insights into tumor suppression: PTEN suppresses tumor formation by restraining the phosphoinositide 3-kinase/AKT pathway," Proceedings of the National Academy of Sciences of the United States of America, vol. 96, no. 8, pp. 4240-4245, 1999.

[28] M. Osaki, M. Oshimura, and H. Ito, "PI3K-Akt pathway: its functions and alterations in human cancer," Apoptosis, vol. 9, no. 6, pp. 667-676, 2004.

[29] N. R. Leslie and C. P. Downes, "PTEN function: how normal cells control it and tumour cells lose it," Biochemical Journal, vol. 382, no. 1, pp. 1-11, 2004.

[30] I. Sansal and W. R. Sellers, "The biology and clinical relevance of the PTEN tumor suppressor pathway," Journal of Clinical Oncology, vol. 22, no. 14, pp. 2954-2963, 2004.

[31] M. L. Sulis and R. Parsons, "PTEN: from pathology to biology," Trends in Cell Biology, vol. 13, no. 9, pp. 478-483, 2003.

[32] T. Maehama and J. E. Dixon, "The tumor suppressor, PTEN/MMAC1, dephosphorylates the lipid second messenger, phosphatidylinositol 3,4,5-trisphosphate," Journal of Biological Chemistry, vol. 273, no. 22, pp. 13375-13378, 1998.

[33] J. Brognard and A. C. Newton, "PHLiPPing the switch on Akt and protein kinase C signaling," Trends in Endocrinology and Metabolism, vol. 19, no. 6, pp. 223-230, 2008.

[34] T. Gao, F. Furnari, and A. C. Newton, "PHLPP: a phosphatase that directly dephosphorylates Akt, promotes apoptosis, and suppresses tumor growth," Molecular Cell, vol. 18, no. 1, pp. 13-24, 2005.

[35] J. Brognard, E. Sierecki, T. Gao, and A. C. Newton, "PHLPP and a second isoform, PHLPP2, differentially attenuate the amplitude of Akt signaling by regulating distinct Akt isoforms," Molecular Cell, vol. 25, no. 6, pp. 917-931, 2007.

[36] J. Liu, H. L. Weiss, P. Rychahou, L. N. Jackson, B. M. Evers, and T. Gao, "Loss of PHLPP expression in colon cancer: role in proliferation and tumorigenesis," Oncogene, vol. 28, no. 7, pp. 994-1004, 2009.

[37] M. Chen, C. Pratt, M. Zeeman et al., "Identification of PHLPP1 as a tumor suppressor reveals the role of feedback activation in PTEN-mutant prostate cancer progression," Cancer Cell, vol. 20, no. 2, pp. 173-186, 2011.
[38] M. Qiao, J. D. Iglehart, and A. B. Pardee, "Metastatic potential of $21 \mathrm{~T}$ human breast cancer cells depends on Akt/protein kinase B activation," Cancer Research, vol. 67, no. 11, pp. 5293-5299, 2007.

[39] D. C. Fingar, S. Salama, C. Tsou, E. Harlow, and J. Blenis, "Mammalian cell size is controlled by mTOR and its downstream targets S6K1 and 4EBP1/eIF4E," Genes and Development, vol. 16, no. 12, pp. 1472-1487, 2002.

[40] D. D. Sarbassov, S. M. Ali, and D. M. Sabatini, "Growing roles for the mTOR pathway," Current Opinion in Cell Biology, vol. 17, no. 6, pp. 596-603, 2005.

[41] L. J. Saucedo and B. A. Edgar, "Why size matters: altering cell size," Current Opinion in Genetics and Development, vol. 12, no. 5, pp. 565-571, 2002.

[42] N. Tapon, K. H. Moberg, and I. K. Hariharan, “The coupling of cell growth to the cell cycle," Current Opinion in Cell Bio$\log y$, vol. 13, no. 6, pp. 731-737, 2001.

[43] A. L. Gartel and K. Shchors, "Mechanisms of c-myc-mediated transcriptional repression of growth arrest genes," Experimental Cell Research, vol. 283, no. 1, pp. 17-21, 2003.

[44] N. N. Ahmed, H. L. Grimes, A. Bellacosa, T. O. Chan, and P. N. Tsichlis, "Transduction of interleukin-2 antiapoptotic and proliferative signals via Akt protein kinase," Proceedings of the National Academy of Sciences of the United States of America, vol. 94, no. 8, pp. 3627-3632, 1997.

[45] R. Sears, F. Nuckolls, E. Haura, Y. Taya, K. Tamai, and J. R. Nevins, "Multiple Ras-dependent phosphorylation pathways regulate Myc protein stability," Genes and Development, vol. 14, no. 19, pp. 2501-2514, 2000.

[46] S. Pelengaris, M. Khan, and G. Evan, "c-MYC: more than just a matter of life and death," Nature Reviews Cancer, vol. 2, no. 10, pp. 764-776, 2002.

[47] J. A. Diehl, M. Cheng, M. F. Roussel, and C. J. Sherr, "Glycogen synthase kinase- $3 \beta$ regulates cyclin D1 proteolysis and subcellular localization," Genes and Development, vol. 12, no. 22, pp. 3499-3511, 1998.

[48] J. R. Alt, J. L. Cleveland, M. Hannink, and J. A. Diehl, "Phosphorylation-dependent regulation of cyclin D1 nuclear export and cyclin D1-dependent cellular transformation," Genes and Development, vol. 14, no. 24, pp. 3102-3114, 2000.

[49] P. Brennan, J. W. Babbage, B. M. T. Burgering, B. Groner, K. Reif, and D. A. Cantrell, "Phosphatidylinositol 3-kinase couples the interleukin-2 receptor to the cell cycle regulator E2F," Immunity, vol. 7, no. 5, pp. 679-689, 1997.

[50] B. P. Zhou, Y. Liao, W. Xia, B. Spohn, M. H. Lee, and M. C. Hung, "Cytoplasmic localization of p21 CIP1/WAF1 by Akt-induced phosphorylation in HER-2/neu-overexpressing cells," Nature Cell Biology, vol. 3, no. 3, pp. 245-252, 2001.

[51] L. Rössig, A. S. Jadidi, C. Urbich, C. Badorff, A. M. Zeiher, and S. Dimmeler, "Akt-dependent phosphorylation of p21Cip1 regulates PCNA binding and proliferation of endothelial cells," Molecular and Cellular Biology, vol. 21, no. 16, pp. 5644-5657, 2001.

[52] Y. Li, D. Dowbenko, and L. A. Lasky, "AKT/PKB phosphorylation of p21Cip/WAF1 enhances protein stability of p21Cip/WAF1 and promotes cell survival," Journal of Biological Chemistry, vol. 277, no. 13, pp. 11352-11361, 2002.

[53] J. M. Jung, J. M. Bruner, S. Ruan et al., "Increased levels of p21(WAF1)/(Cip1) in human brain tumors," Oncogene, vol. 11, no. 10, pp. 2021-2028, 1995.

[54] R. H. Medema, G. J. P. L. Kops, J. L. Bos, and B. M. T. Burgering, "AFX-like Forkhead transcription factors mediate cell-cycle regulation by Ras and PKB through p27(kip1)," Nature, vol. 404, no. 6779, pp. 782-787, 2000. 
[55] G. Viglietto, M. L. Motti, P. Bruni et al., "Cytoplasmic relocalization and inhibition of the cyclin-dependent kinase inhibitor p27kip1 by PKB/Akt-mediated phosphorylation in breast cancer," Nature Medicine, vol. 8, no. 10, pp. 1136-1144, 2002.

[56] I. Shin, F. M. Yakes, F. Rojo et al., "PKB/Akt mediates cellcycle progression by phosphorylation of p27Kip1 at threonine 157 and modulation of its cellular localization," Nature Medicine, vol. 8, no. 10, pp. 1145-1152, 2002.

[57] J. Liang, J. Zubovitz, T. Petrocelli et al., "PKB/Akt phosphorylates p27, impairs nuclear import of p27 and opposes p27mediated G1 arrest," Nature Medicine, vol. 8, no. 10, pp. 1153-1160, 2002.

[58] N. Fujita, S. Sato, K. Katayama, and T. Tsuruo, "Akt-dependent phosphorylation of p27Kip1 promotes binding to 14-33 and cytoplasmic localization," Journal of Biological Chemistry, vol. 277, no. 32, pp. 28706-28713, 2002.

[59] G. Rodier, A. Montagnoli, L. Di Marcotullio et al., "p27 cytoplasmic localization is regulated by phosphorylation on Ser10 and is not a prerequisite for its proteolysis," $E M B O$ Journal, vol. 20, no. 23, pp. 6672-6682, 2001.

[60] T. Sekimoto, M. Fukumoto, and Y. Yoneda, "14-3-3 suppresses the nuclear localization of threonine 157-phosphorylated p27Kip1," EMBO Journal, vol. 23, no. 9, pp. 19341942, 2004.

[61] M. Ciaparrone, H. Yamamoto, Y. Yao et al., "Localization and expression of p27(KIP1) in multistage colorectal carcinogenesis," Cancer Research, vol. 58, no. 1, pp. 114-122, 1998.

[62] S. P. Singh, J. Lipman, H. Goldman et al., "Loss or altered subcellular localization of p27 in Barrett's associated adenocarcinoma," Cancer Research, vol. 58, no. 8, pp. 1730-1735, 1998.

[63] H. K. Lin, G. Wang, Z. Chen et al., "Phosphorylation-dependent regulation of cytosolic localization and oncogenic function of Skp2 by Akt/PKB," Nature Cell Biology, vol. 11, no. 4, pp. 420-432, 2009.

[64] D. Gao, H. Inuzuka, A. Tseng, R. Y. Chin, A. Toker, and W. Wei, "Phosphorylation by Aktl promotes cytoplasmic localization of Skp2 and impairs APCCdh1-mediated Skp2 destruction," Nature Cell Biology, vol. 11, no. 4, pp. 397-408, 2009.

[65] A. C. Carrano, E. Eytan, A. Hershko, and M. Pagano, "SKP2 is required for ubiquitin-mediated degradation of the CDK inhibitor p27," Nature Cell Biology, vol. 1, no. 4, pp. 193-199, 1999.

[66] H. Sutterlüty, E. Chatelain, A. Marti et al., "p45SKP2 promotes p27Kip1 degradation and induces $S$ phase in quiescent cells," Nature Cell Biology, vol. 1, no. 4, pp. 207-214, 1999.

[67] D. Ganoth, G. Bornstein, T. K. Ko et al., "The cell-cycle regulatory protein Cks1 is required for SCFSkp2-mediated ubiquitinylation of p27," Nature Cell Biology, vol. 3, no. 3, pp. 321-324, 2001.

[68] C. Spruck, H. Strohmaier, M. Watson et al., "A CDK-independent function of mammalian Cks1: targeting of SCFSkp2 to the CDK inhibitor p27Kip1," Molecular Cell, vol. 7, no. 3, pp. 639-650, 2001.

[69] A. J. Levine, "p53, the cellular gatekeeper for growth and division," Cell, vol. 88, no. 3, pp. 323-331, 1997.

[70] S. Bates and K. H. Vousden, "Mechanisms of p53-mediated apoptosis," Cellular and Molecular Life Sciences, vol. 55, no. 1, pp. 28-37, 1999.

[71] M. H. G. Kubbutat, S. N. Jones, and K. H. Vousden, "Regulation of p53 stability by Mdm2," Nature, vol. 387, no. 6630, pp. 299-303, 1997.
[72] Y. Haupt, R. Maya, A. Kazaz, and M. Oren, "Mdm2 promotes the rapid degradation of p53," Nature, vol. 387, no. 6630, pp. 296-299, 1997.

[73] M. Ashcroft, R. L. Ludwig, D. B. Woods et al., "Phosphorylation of HDM2 by Akt," Oncogene, vol. 21, no. 13, pp. 19551962, 2002.

[74] Y. Ogawara, S. Kishishita, T. Obata et al., "Akt enhances Mdm2-mediated ubiquitination and degradation of p53," Journal of Biological Chemistry, vol. 277, no. 24, pp. 2184321850, 2002.

[75] L. D. Mayo and D. B. Donner, "A phosphatidylinositol 3kinase/Akt pathway promotes translocation of Mdm2 from the cytoplasm to the nucleus," Proceedings of the National Academy of Sciences of the United States of America, vol. 98, no. 20, pp. 11598-11603, 2001.

[76] H. Kawai, V. Lopez-Pajares, M. M. Kim, D. Wiederschain, and Z. M. Yuan, "RING domain-mediated interaction is a requirement for MDM2's E3 ligase activity," Cancer Research, vol. 67, no. 13, pp. 6026-6030, 2007.

[77] L. K. Linares, A. Hengstermann, A. Ciechanover, S. Müller, and M. Scheffner, "HdmX stimulates Hdm2-mediated ubiquitination and degradation of p53," Proceedings of the National Academy of Sciences of the United States of America, vol. 100, no. 21, pp. 12009-12014, 2003.

[78] V. Lopez-Pajares, M. M. Kim, and Z. M. Yuan, "Phosphorylation of MDMX mediated by Akt leads to stabilization and induces 14-3-3 binding," Journal of Biological Chemistry, vol. 283, no. 20, pp. 13707-13713, 2008.

[79] E. Shtivelman, J. Sussman, and D. Stokoe, "A role for PI 3kinase and PKB activity in the G2/M phase of the cell cycle," Current Biology, vol. 12, no. 11, pp. 919-924, 2002.

[80] E. S. Kandel, J. Skeen, N. Majewski et al., "Activation of Akt/protein kinase B overcomes a G2/M cell cycle checkpoint induced by DNA damage," Molecular and Cellular Biology, vol. 22, no. 22, pp. 7831-7841, 2002.

[81] C. Karlsson, S. Katich, A. Hagting, I. Hoffmann, and J. Pines, "Cdc25B and Cdc25C differ markedly in their properties as initiators of mitosis," Journal of Cell Biology, vol. 146, no. 3, pp. 573-583, 1999.

[82] V. Baldin, N. Theis-Febvre, C. Benne et al., "PKB/Akt phosphorylates the CDC25B phosphatase and regulates its intracellular localisation," Biology of the Cell, vol. 95, no. 8, pp. 547-554, 2003.

[83] I. Nilsson and I. Hoffmann, "Cell cycle regulation by the Cdc25 phosphatase family," Progress in cell cycle research, vol. 4, pp. 107-114, 2000.

[84] N. Davezac, V. Baldin, B. Gabrielli et al., "Regulation of CDC25B phosphatases subcellular localization," Oncogene, vol. 19, no. 18, pp. 2179-2185, 2000.

[85] K. Katayama, N. Fujita, and T. Tsuruo, "Akt/protein kinase B-dependent phosphorylation and inactivation of WEE1Hu promote cell cycle progression at G2/M transition," Molecular and Cellular Biology, vol. 25, no. 13, pp. 5725-5737, 2005.

[86] E. Okumura, T. Fukuhara, H. Yoshida et al., "Akt inhibits Myt1 in the signalling pathway that leads to meiotic G2/Mphase transition," Nature Cell Biology, vol. 4, no. 2, pp. 111116, 2002.

[87] S. Maddika, S. R. Sande, E. Wiechec, L. L. Hansen, S. Wesselborg, and M. Los, "Akt-mediated phosphorylation of CDK2 regulates its dual role in cell cycle progression and apoptosis," Journal of Cell Science, vol. 121, no. 7, pp. 979-988, 2008.

[88] S. Maddika, S. Panigrahi, E. Wiechec et al., "Unscheduled Akt-triggered activation of cyclin-dependent kinase 2 as a key 
effector mechanism of apoptin's anticancer toxicity," Molecular and Cellular Biology, vol. 29, no. 5, pp. 1235-1248, 2009.

[89] J. Brognard, A. S. Clark, Y. Ni, and P. A. Dennis, "Akt/pbotein kinace B is constitutively active in non-small cell lung cancer cells and promotes cellular survival and resistance to chemotherapy and radiation," Cancer Research, vol. 61, no. 10, pp. 3986-3997, 2001.

[90] D. Lu, J. Huang, and A. Basu, "Protein kinase Ce activates protein kinase $\mathrm{B} / \mathrm{Akt}$ via DNA-PK to protect against tumor necrosis factor- $\alpha$-induced cell death," Journal of Biological Chemistry, vol. 281, no. 32, pp. 22799-22807, 2006.

[91] J. Guinea Viniegra, N. Martínez, P. Modirassari et al., "Full activation of $\mathrm{PKB} / \mathrm{Akt}$ in response to insulin or ionizing radiation is mediated through ATM," Journal of Biological Chemistry, vol. 280, no. 6, pp. 4029-4036, 2005.

[92] L. Bozulic, B. Surucu, D. Hynx, and B. A. Hemmings, "PKB $\alpha /$ Akt1 Acts Downstream of DNA-PK in the DNA Double-Strand Break Response and Promotes Survival," Molecular Cell, vol. 30, no. 2, pp. 203-213, 2008.

[93] S. Caporali, L. Levati, G. Starace et al., "AKT is activated in an ataxia-telangiectasia and Rad3-related-dependent manner in response to temozolomide and confers protection against drug-induced cell growth inhibition," Molecular Pharmacology, vol. 74, no. 1, pp. 173-183, 2008.

[94] S. D. Spacey, R. A. Gatti, and G. Bebb, "The molecular basis and clinical management of ataxia telangiectasia," Canadian Journal of Neurological Sciences, vol. 27, no. 3, pp. 184-191, 2000.

[95] C. Barlow, S. Hirotsune, R. Paylor et al., "Atm-deficient mice: a paradigm of ataxia telangiectasia," Cell, vol. 86, no. 1, pp. 159-171, 1996.

[96] K. A. Boehme, R. Kulikov, and C. Blattner, "p53 stabilization in response to DNA damage requires Akt/PKB and DNAPK," Proceedings of the National Academy of Sciences of the United States of America, vol. 105, no. 22, pp. 7785-7790, 2008.

[97] S. P. Lees-Miller, "PIKK-ing a new partner: a new role for PKB in the DNA damage response," Cancer Cell, vol. 13, no. 5, pp. 379-380, 2008.

[98] A. Toker, "Akt signaling: a damaging interaction makes good," Trends in Biochemical Sciences, vol. 33, no. 8, pp. 356359, 2008.

[99] F. W. King, J. Skeen, N. Hay, and E. Shtivelman, "Inhibition of Chk1 by activated PKB/Akt," Cell Cycle, vol. 3, no. 5, pp. 634-637, 2004.

[100] I. Tonic, W. N. Yu, Y. Park, C. C. Chen, and N. Hay, "Akt activation emulates $\mathrm{Chk} 1$ inhibition and $\mathrm{Bcl} 2$ overexpression and abrogates $\mathrm{G} 2$ cell cycle checkpoint by inhibiting BRCA1 foci," Journal of Biological Chemistry, vol. 285, no. 31, pp. 23790-23798, 2010.

[101] J. Puc, M. Keniry, H. S. Li et al., "Lack of PTEN sequesters CHK1 and initiates genetic instability," Cancer Cell, vol. 7, no. 2, pp. 193-204, 2005.

[102] M. K. Henry, J. T. Lynch, A. K. Eapen, and F. W. Quelle, "DNA damage-induced cell-cycle arrest of hematopoietic cells is overridden by activation of the PI-3 kinase/Akt signaling pathway," Blood, vol. 98, no. 3, pp. 834-841, 2001.

[103] Y. Hirose, M. Katayama, O. K. Mirzoeva, M. S. Berger, and R. O. Pieper, "Akt activation suppresses Chk2-mediated, methylating agent-induced G 2 arrest and protects from temozolomide-induced mitotic catastrophe and cellular senescence," Cancer Research, vol. 65, no. 11, pp. 4861-4869, 2005.
[104] A. Sancar, L. A. Lindsey-Boltz, K. Ünsal-Kaçmaz, and S. Linn, "Molecular mechanisms of mammalian DNA repair and the DNA damage checkpoints," Annual Review of Biochemistry, vol. 73, pp. 39-85, 2004.

[105] T. Helleday, J. Lo, D. C. van Gent, and B. P. Engelward, "DNA double-strand break repair: from mechanistic understanding to cancer treatment," DNA Repair, vol. 6, no. 7, pp. 923-935, 2007.

[106] J. Guirouilh-Barbat, S. Huck, P. Bertrand et al., "Impact of the KU80 pathway on NHEJ-induced genome rearrangements in mammalian cells," Molecular Cell, vol. 14, no. 5, pp. 611-623, 2004.

[107] J. M. Daley, P. L. Palmbos, D. Wu, and T. E. Wilson, "Nonhomologous end joining in yeast," Annual Review of Genetics, vol. 39, pp. 431-451, 2005.

[108] M. R. Lieber, Y. Ma, U. Pannicke, and K. Schwarz, "Mechanism and regulation of human non-homologous DNA endjoining," Nature Reviews Molecular Cell Biology, vol. 4, no. 9, pp. 712-720, 2003.

[109] E. Sonoda, H. Hochegger, A. Saberi, Y. Taniguchi, and S. Takeda, "Differential usage of non-homologous end-joining and homologous recombination in double strand break repair," DNA Repair, vol. 5, no. 9-10, pp. 1021-1029, 2006.

[110] L. Wohlbold and R. P. Fisher, "Behind the wheel and under the hood: functions of cyclin-dependent kinases in response to DNA damage," DNA Repair, vol. 8, no. 9, pp. 1018-1024, 2009.

[111] M. Toulany, U. Kasten-Pisula, I. Brammer et al., "Blockage of epidermal growth factor receptor-phosphatidylinositol 3kinase-AKT signaling increases radiosensitivity of K-RAS mutated human tumor cells in vitro by affecting DNA repair," Clinical Cancer Research, vol. 12, no. 13, pp. 4119-4126, 2006.

[112] G. D. Kao, Z. Jiang, A. M. Fernandes, A. K. Gupta, and A. Maity, "Inhibition of phosphatidylinositol-3-OH kinase/Akt signaling impairs DNA repair in glioblastoma cells following ionizing radiation," Journal of Biological Chemistry, vol. 282, no. 29, pp. 21206-21212, 2007.

[113] M. Toulany, R. Kehlbach, U. Florczak et al., "Targeting of AKT1 enhances radiation toxicity of human tumor cells by inhibiting DNA-PKcs-dependent DNA double-strand break repair," Molecular Cancer Therapeutics, vol. 7, no. 7, pp. 1772-1781, 2008.

[114] M. Toulany, R. Kehlbach, H. P. Rodemann, and H. Mozdarani, "Radiocontrast media affect radiation-induced DNA damage repair in vitro and in vivo by affecting Akt signalling," Radiotherapy and Oncology, vol. 94, no. 1, pp. 110116, 2010.

[115] S. E. Golding, R. N. Morgan, B. R. Adams, A. J. Hawkins, L. F. Povirk, and K. Valerie, "Pro-survival AKT and ERK signaling from EGFR and mutant EGFRvIII enhances DNA doublestrand break repair in human glioma cells," Cancer Biology and Therapy, vol. 8, no. 8, pp. 730-738, 2009.

[116] B. P. C. Chen, N. Uematsu, J. Kobayashi et al., "Ataxia telangiectasia mutated (ATM) is essential for DNA-PKcs phosphorylations at the Thr-2609 cluster upon DNA double strand break," Journal of Biological Chemistry, vol. 282, no. 9, pp. 6582-6587, 2007.

[117] M. F. Lavin and S. Kozlov, "DNA damage-induced signalling in ataxia-telangiectasia and related syndromes," Radiotherapy and Oncology, vol. 83, no. 3, pp. 231-237, 2007.

[118] J. Feng, J. Park, P. Cron, D. Hess, and B. A. Hemmings, "Identification of a PKB/Akt hydrophobic motif Ser-473 kinase as DNA-dependent protein kinase," Journal of Biological Chemistry, vol. 279, no. 39, pp. 41189-41196, 2004. 
[119] C. Richardson, J. M. Stark, M. Ommundsen, and M. Jasin, "Rad51 overexpression promotes alternative double-strand break repair pathways and genome instability," Oncogene, vol. 23, no. 2, pp. 546-553, 2004.

[120] A. J. R. Bishop and R. H. Schiestl, "Homologous recombination and its role in carcinogenesis," Journal of Biomedicine and Biotechnology, vol. 2002, no. 2, pp. 75-85, 2002.

[121] I. Plo, C. Laulier, L. Gauthier, F. Lebrun, F. Calvo, and B. S. Lopez, "AKT1 inhibits homologous recombination by inducing cytoplasmic retention of BRCA1 and RAD5," Cancer Research, vol. 68, no. 22, pp. 9404-9412, 2008.

[122] N. Xu, N. Hegarat, E. J. Black, M. T. Scott, H. Hochegger, and D. A. Gillespie, "Akt/PKB suppresses DNA damage processing and checkpoint activation in late G2," Journal of Cell Biology, vol. 190, no. 3, pp. 297-306, 2010.

[123] B. Barré and N. D. Perkins, "A cell cycle regulatory network controlling NF- $\kappa \mathrm{B}$ subunit activity and function," $E M B O$ Journal, vol. 26, no. 23, pp. 4841-4855, 2007.

[124] A. Pedram, M. Razandi, A. J. Evinger, E. Lee, and E. R. Levin, "Estrogen inhibits ATR signaling to cell cycle checkpoints and DNA repair," Molecular Biology of the Cell, vol. 20, no. 14, pp. 3374-3389, 2009.

[125] S. B. Lee, I. S. Kwon, J. Park et al., "Ribosomal protein S3, a new substrate of Akt, serves as a signal mediator between neuronal apoptosis and DNA repair," Journal of Biological Chemistry, vol. 285, no. 38, pp. 29457-29468, 2010.

[126] I. Plo and B. Lopez, "AKT1 represses gene conversion induced by different genotoxic stresses and induces supernumerary centrosomes and aneuploidy in hamster ovary cells," Oncogene, vol. 28, no. 22, pp. 2231-2237, 2009.

[127] M. Walker, E. J. Black, V. Oehler, D. A. Gillespie, and M. T. Scott, "Chk1 C-terminal regulatory phosphorylation mediates checkpoint activation by de-repression of Chk1 catalytic activity," Oncogene, vol. 28, no. 24, pp. 2314-2323, 2009.

[128] G. Zachos, M. D. Rainey, and D. A. F. Gillespie, "Chk1deficient tumour cells are viable but exhibit multiple checkpoint and survival defects," EMBO Journal, vol. 22, no. 3, pp. 713-723, 2003.

[129] G. Zachos, M. D. Rainey, and D. A. F. Gillespie, "Chk1dependent S-M checkpoint delay in vertebrate cells is linked to maintenance of viable replication structures," Molecular and Cellular Biology, vol. 25, no. 2, pp. 563-574, 2005.

[130] J. Smith, L. Mun Tho, N. Xu, and D. A. Gillespie, “The ATMChk2 and ATR-Chk1 pathways in DNA damage signaling and cancer," Advances in Cancer Research, vol. 108, no. C, pp. 73$112,2010$.

[131] V. Garcia, K. Furuya, and A. M. Carr, "Identification and functional analysis of TopBP1 and its homologs," DNA Repair, vol. 4, no. 11, pp. 1227-1239, 2005.

[132] A. Kumagai, J. Lee, H. Y. Yoo, and W. G. Dunphy, “TopBP1 activates the ATR-ATRIP complex," Cell, vol. 124, no. 5, pp. 943-955, 2006.

[133] L. I. Toledo, M. Murga, P. Gutierrez-Martinez, R. Soria, and O. Fernandez-Capetillo, "ATR signaling can drive cells into senescence in the absence of DNA breaks," Genes and Development, vol. 22, no. 3, pp. 297-302, 2008.

[134] K. Liu, J. C. Paik, B. Wang, F. T. Lin, and W. C. Lin, "Regulation of TopBP1 oligomerization by Akt/PKB for cell survival," EMBO Journal, vol. 25, no. 20, pp. 4795-4807, 2006.

[135] S. Altiok, D. Batt, N. Altiokl et al., "Heregulin induces phosphorylation of BRCA1 through phosphatidylinositol 3kinase/AKT in breast cancer cells," Journal of Biological Chemistry, vol. 274, no. 45, pp. 32274-32278, 1999.
[136] C. V. Hinton, L. D. Fitzgerald, and M. E. Thompson, "Phosphatidylinositol 3-kinase/Akt signaling enhances nuclear localization and transcriptional activity of BRCA1," Experimental Cell Research, vol. 313, no. 9, pp. 1735-1744, 2007.

[137] T. Miralem and H. K. Avraham, "Extracellular matrix enhances heregulin-dependent BRCA1 phosphorylation and suppresses BRCA1 expression through its C terminus," Molecular and Cellular Biology, vol. 23, no. 2, pp. 579-593, 2003.

[138] T. Xiang, A. Ohashi, Y. Huang et al., "Negative regulation of AKT activation by BRCA1," Cancer Research, vol. 68, no. 24, pp. 10040-10044, 2008.

[139] T. Schäfer, B. Maco, E. Petfalski et al., "Hrr25-dependent phosphorylation state regulates organization of the pre-40S subunit," Nature, vol. 441, no. 7093, pp. 651-655, 2006.

[140] D. T. Grabowski, W. A. Deutsch, D. Derda, and M. R. Kelley, "Drosophila AP3, a presumptive DNA repair protein, is homologous to human ribosomal associated protein PO," Nucleic Acids Research, vol. 19, no. 15, p. 4297, 1991.

[141] J. Kim, L. S. Chubatsu, A. Admon, J. Stahl, R. Fellous, and S. Linn, "Implication of mammalian ribosomal protein S3 in the processing of DNA damage," Journal of Biological Chemistry, vol. 270, no. 23, pp. 13620-13629, 1995.

[142] S. H. Kim, J. Y. Lee, and J. Kim, "Characterization of a wide range base-damage-endonuclease activity of mammalian rpS3," Biochemical and Biophysical Research Communications, vol. 328, no. 4, pp. 962-967, 2005.

[143] V. Hegde, S. Yadavilli, and W. A. Deutsch, "Knockdown of ribosomal protein S3 protects human cells from genotoxic stress," DNA Repair, vol. 6, no. 1, pp. 94-99, 2007.

[144] S. N. Radyuk, K. Michalak, I. Rebrin, R. S. Sohal, and W. C. Orr, "Effects of ectopic expression of Drosophila DNA glycosylases dOgg1 and RpS3 in mitochondria," Free Radical Biology and Medicine, vol. 41, no. 5, pp. 757-764, 2006.

[145] R. Deng, J. Tang, J. G. Ma et al., "PKB/Akt promotes DSB repair in cancer cells through upregulating Mre11 expression following ionizing radiation," Oncogene, vol. 30, pp. 944-955, 2011.

[146] M. S. Tsai, Y. H. Kuo, Y. F. Chiu, Y. C. Su, and Y. W. Lin, "Down-regulation of Rad51 expression overcomes drug resistance to gemcitabine in human non-small-cell lung cancer cells," Journal of Pharmacology and Experimental Therapeutics, vol. 335, no. 3, pp. 830-840, 2010.

[147] J. C. Ko, S. C. Ciou, J. Y. Jhan et al., "Roles of MKK1/2ERK1/2 and phosphoinositide 3-kinase-AKT signaling pathways in erlotinib-induced Rad51 suppression and cytotoxicity in human non-small cell lung cancer cells," Molecular Cancer Research, vol. 7, no. 8, pp. 1378-1389, 2009.

[148] B. T. Hennessy, D. L. Smith, P. T. Ram, Y. Lu, and G. B. Mills, "Exploiting the PI3K/AKT pathway for cancer drug discovery," Nature Reviews Drug Discovery, vol. 4, no. 12, pp. 988-1004, 2005.

[149] D. Hanahan and R. A. Weinberg, "The hallmarks of cancer," Cell, vol. 100, no. 1, pp. 57-70, 2000.

[150] E. Calvo, M. V. Bolós, and E. Grande, "Multiple roles and therapeutic implications of Akt signaling in cancer," OncoTargets and Therapy, vol. 2, pp. 135-150, 2009.

[151] D. Haas-Kogan, N. Shalev, M. Wong, G. Mills, G. Yount, and D. Stokoe, "Protein kinase B (PKB/Akt) activity is elevated in glioblastoma cells due to mutation of the tumor suppressor PTEN/MMAC," Current Biology, vol. 8, no. 21, pp. 11951198, 1998.

[152] H. K. Roy, B. F. Olusola, D. L. Clemens et al., "AKT proto-oncogene overexpression is an early event during sporadic colon 
carcinogenesis," Carcinogenesis, vol. 23, no. 1, pp. 201-205, 2002.

[153] I. U. Ali, L. M. Schriml, and M. Dean, "Mutational spectra of PTEN/MMAC1 gene: a tumor suppressor with lipid phosphatase activity," Journal of the National Cancer Institute, vol. 91, no. 22, pp. 1922-1932, 1999.

[154] I. Vivanco and C. L. Sawyers, "The phosphatidylinositol 3-kinase-AKT pathway in human cancer," Nature Reviews Cancer, vol. 2, no. 7, pp. 489-501, 2002.

[155] D. W. Parsons, T. L. Wang, Y. Samuels et al., "Colorectal cancer: mutations in a signalling pathway," Nature, vol. 436, no. 7052, p. 792, 2005.

[156] A. Carnero, “The PKB/AKT pathway in cancer," Current Pharmaceutical Design, vol. 16, no. 1, pp. 34-44, 2010.

[157] J. Woenckhaus, K. Steger, E. Werner et al., "Genomic gain of PIK3CA and increased expression of pI I 0alpha are associated with progression of dysplasia into invasive squamous cell carcinoma," Journal of Pathology, vol. 198, no. 3, pp. 335-342, 2002.

[158] Y. Samuels, Z. Wang, A. Bardelli et al., "High frequency of mutations of the PIK3CA gene in human cancers," Science, vol. 304, no. 5670, p. 554, 2004.

[159] L. Shayesteh, Y. Lu, W. L. Kuo et al., "PlK3CA is implicated as an oncogene in ovarian cancer," Nature Genetics, vol. 21, no. 1, pp. 99-102, 1999.

[160] Y. Y. Ma, S. J. Wei, Y. C. Lin et al., "PIK3CA as an oncogene in cervical cancer," Oncogene, vol. 19, no. 23, pp. 2739-2744, 2000.

[161] D. S. Byun, K. Cho, B. K. Ryu et al., "Frequent monoallelic deletion of PTEN and its reciprocal associatioin with PIK3CA amplification in gastric carcinoma," International Journal of Cancer, vol. 104, no. 3, pp. 318-327, 2003.

[162] C. B. Knobbe and G. Reifenberger, "Genetic alterations and aberrant expression of genes related to the phosphatidylinositol-3' kinase/protein kinase B (Akt) signal transduction pathway in glioblastomas," Brain Pathology, vol. 13, no. 4, pp. 507-518, 2003.

[163] G. Giannini, E. Ristori, F. Cerignoli et al., "Human MRE11 is inactivated in mismatch repair-deficient cancers," EMBO Reports, vol. 3, no. 3, pp. 248-254, 2002.

[164] A. K. C. Wong, P. A. Ormonde, R. Pero et al., "Characterization of a carboxy-terminal BRCA1 interacting protein," Oncogene, vol. 17, no. 18, pp. 2279-2285, 1998.

[165] J. H. J. Hoeijmakers, "DNA damage, aging, and cancer," New England Journal of Medicine, vol. 361, no. 15, pp. 1475-1485, 2009.

[166] T. Helleday, E. Petermann, C. Lundin, B. Hodgson, and R. A. Sharma, "DNA repair pathways as targets for cancer therapy," Nature Reviews Cancer, vol. 8, no. 3, pp. 193-204, 2008.

[167] A. K. Gupta, V. J. Bakanauskas, G. J. Cerniglia et al., "The Ras radiation resistance pathway," Cancer Research, vol. 61, no. 10, pp. 4278-4282, 2001.

[168] T. M. Grana, E. V. Rusyn, H. Zhou, C. I. Sartor, and A. D. Cox, "Ras mediates radioresistance through both phosphatidylinositol 3-kinase-dependent and Raf-dependent but mitogenactivated protein kinase/extracellular signal-regulated kinase kinase-independent signaling pathways," Cancer Research, vol. 62, no. 14, pp. 4142-4150, 2002.

[169] E. Edwards, L. Geng, J. Tan, H. Onishko, E. Donnelly, and D. E. Hallahan, "Phosphatidylinositol 3-kinase/Akt signaling in the response of vascular endothelium to ionizing radiation," Cancer Research, vol. 62, no. 16, pp. 4671-4677, 2002.
[170] A. R. Gottschalk, A. Doan, J. L. Nakamura, D. Stokoe, and D. A. Haas-Kogan, "Inhibition of phosphatidylinositol-3-kinase causes increased sensitivity to radiation through a PKBdependent mechanism," International Journal of Radiation Oncology Biology Physics, vol. 63, no. 4, pp. 1221-1227, 2005.

[171] A. K. Gupta, G. J. Cerniglia, R. Mick et al., "Radiation sensitization of human cancer cells in vivo by inhibiting the activity of PI3K using LY294002," International Journal of Radiation Oncology Biology Physics, vol. 56, no. 3, pp. 846-853, 2003.

[172] A. K. Gupta, W. G. McKenna, C. N. Weber et al., "Local recurrence in head and neck cancer: relationship to radiation resistance and signal transduction," Clinical Cancer Research, vol. 8, no. 3, pp. 885-892, 2002.

[173] I. A. Kim, S. S. Bae, A. Fernandes et al., "Selective inhibition of Ras, phosphoinositide 3 kinase, and Akt isoforms increases the radiosensitivity of human carcinoma cell lines," Cancer Research, vol. 65, no. 17, pp. 7902-7910, 2005.

[174] C. M. Lee, C. B. Fuhrman, V. Planelles et al., "Phosphatidylinositol 3-kinase inhibition by LY294002 radiosensitizes human cervical cancer cell lines," Clinical Cancer Research, vol. 12, no. 1, pp. 250-256, 2006.

[175] B. Li, M. Yuan, I. A. Kim, C. M. Chang, E. J. Bernhard, and H. K. G. Shu, "Mutant epidermal growth factor receptor displays increased signaling through the phosphatidylinositol-3 kinase/AKT pathway and promotes radioresistance in cells of astrocytic origin," Oncogene, vol. 23, no. 26, pp. 4594-4602, 2004.

[176] A. S. Clark, K. West, S. Streicher, and P. A. Dennis, "Constitutive and inducible Akt activity promotes resistance to chemotherapy, trastuzumab, or tamoxifen in breast cancer cells," Molecular cancer therapeutics, vol. 1, no. 9, pp. 707717, 2002.

[177] J. J. Wallin, J. Guan, W. W. Prior et al., "Nuclear phospho-Akt increase predicts synergy of PI3K inhibition and doxorubicin in breast and ovarian cancer," Science Translational Medicine, vol. 2, no. 48, Article ID 48ra66, 2010.

[178] J. M. Tang, Q. Y. He, R. X. Guo, and X. J. Chang, "Phosphorylated Akt overexpression and loss of PTEN expression in nonsmall cell lung cancer confers poor prognosis," Lung Cancer, vol. 51, no. 2, pp. 181-191, 2006.

[179] S. K. Pal, K. Reckamp, H. Yu, and R. A. Figlin, "Akt inhibitors in clinical development for the treatment of cancer," Expert Opinion on Investigational Drugs, vol. 19, no. 11, pp. 13551366, 2010

[180] J. LoPiccolo, C. A. Granville, J. J. Gills, and P. A. Dennis, "Targeting Akt in cancer therapy," Anti-Cancer Drugs, vol. 18, no. 8, pp. 861-874, 2007.

[181] C. W. Lindsley, "The Akt/PKB family of protein kinases: a review of small molecule inhibitors and progress towards target validation: a 2009 update," Current Topics in Medicinal Chemistry, vol. 10, no. 4, pp. 458-477, 2010.

[182] S. B. Kondapaka, S. S. Singh, G. P. Dasmahapatra, E. A. Sausville, and K. K. Roy, "Perifosine, a novel alkylphospholipid, inhibits protein kinase B activation," Molecular Cancer Therapeutics, vol. 2, no. 11, pp. 1093-1103, 2003.

[183] L. van Ummersen, K. Binger, J. Volkman et al., "A phase I trial of perifosine (NSC 639966) on a loading dose/maintenance dose schedule in patients with advanced cancer," Clinical Cancer Research, vol. 10, no. 22, pp. 7450-7456, 2004.

[184] N. Komai, Y. Morita, T. Sakuta, A. Kuwabara, and N. Kashihara, "Anti-tumor necrosis factor therapy increases serum adiponectin levels with the improvement of endothelial dysfunction in patients with rheumatoid arthritis," Modern Rheumatology, vol. 17, no. 5, pp. 385-390, 2007. 
[185] S. F. Barnett, M. T. Bilodeau, and C. W. Lindsley, "The Akt/PKB family of protein kinases: a review of small molecule inhibitors and progress towards target validation," Current Topics in Medicinal Chemistry, vol. 5, no. 2, pp. 109-125, 2005.

[186] C. W. Lindsley, S. F. Barnett, M. Yaroschak, M. T. Bilodeau, and M. E. Layton, "Recent progress in the development of ATP-competitive and allosteric Akt kinase inhibitors," Current Topics in Medicinal Chemistry, vol. 7, no. 14, pp. 13491363, 2007.

[187] H. Hirai, H. Sootome, Y. Nakatsuru et al., "MK-2206, an allosteric akt inhibitor, enhances antitumor efficacy by standard chemotherapeutic agents or molecular targeted drugs in vitro and in vivo," Molecular Cancer Therapeutics, vol. 9, no. 7, pp. 1956-1967, 2010.

[188] T. A. Yap et al., "First-in-man clinical trial of the oral panAKT inhibitor MK-2206 in patients with advanced solid tumors," Journal of Clinical Oncology, vol. 29, no. 35, pp. 46884695, 2011.

[189] B. Markman, R. Dienstmann, and J. Tabernero, "Targeting the PI3K/Akt/mTOR pathway-beyond rapalogs," Oncotarget, vol. 1, no. 7, pp. 530-543, 2010.

[190] NCT00460278, "A Safety and Efficacy Study of RX-0201 Plus Gemcitabine in Metastatic Pancreatic Cancer," US National Institute of Health, Bethesda, Md, USA, 2009, http:// clinicaltrials.gov/ct2/show/NCT01028495.

[191] P. Wu and Y. Z. Hu, "PI3K/Akt/mTOR pathway inhibitors in cancer: a perspective on clinical progress," Current Medicinal Chemistry, vol. 17, no. 35, pp. 4326-4341, 2010. 


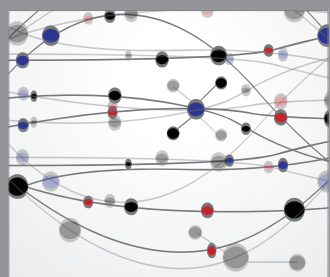

The Scientific World Journal
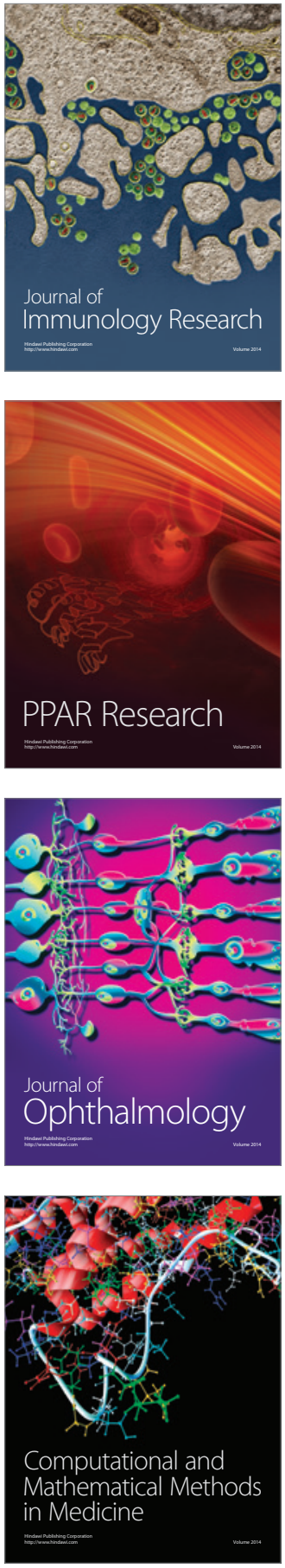

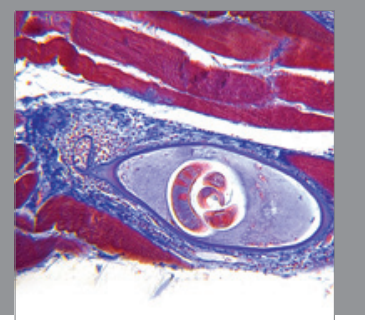

Gastroenterology

Research and Practice
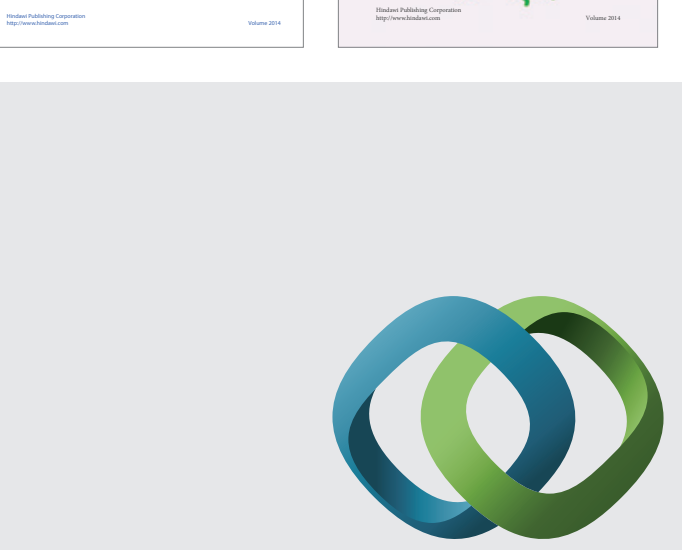

\section{Hindawi}

Submit your manuscripts at

http://www.hindawi.com
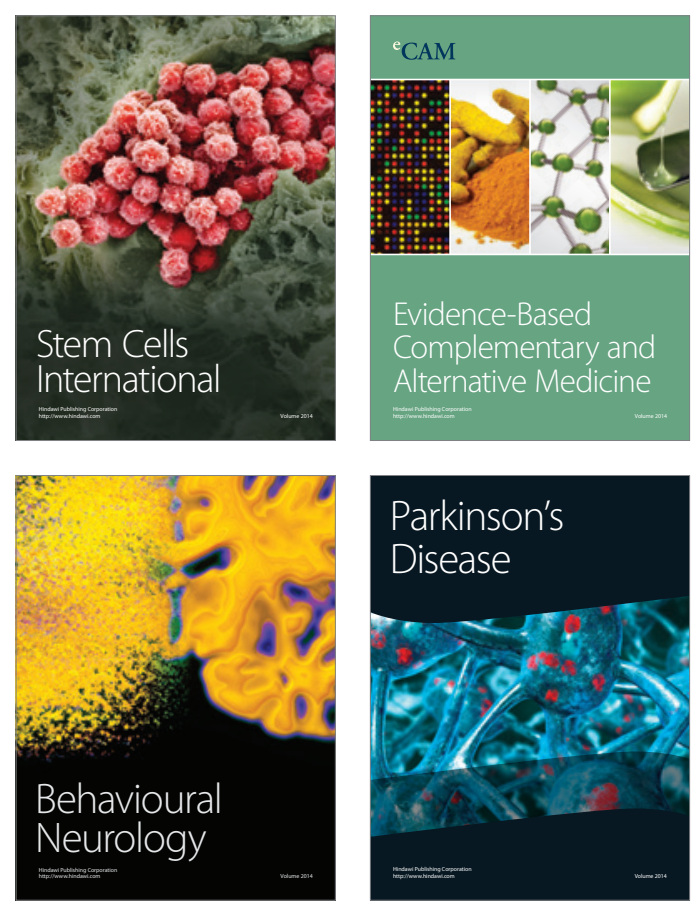

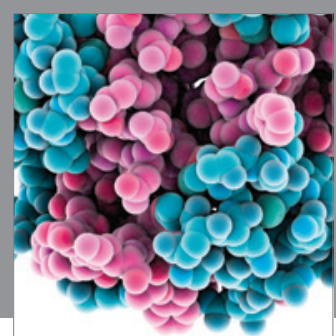

Journal of
Diabetes Research

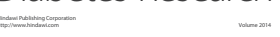

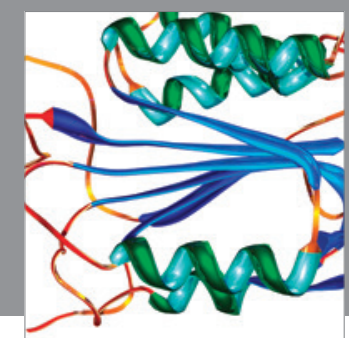

Disease Markers
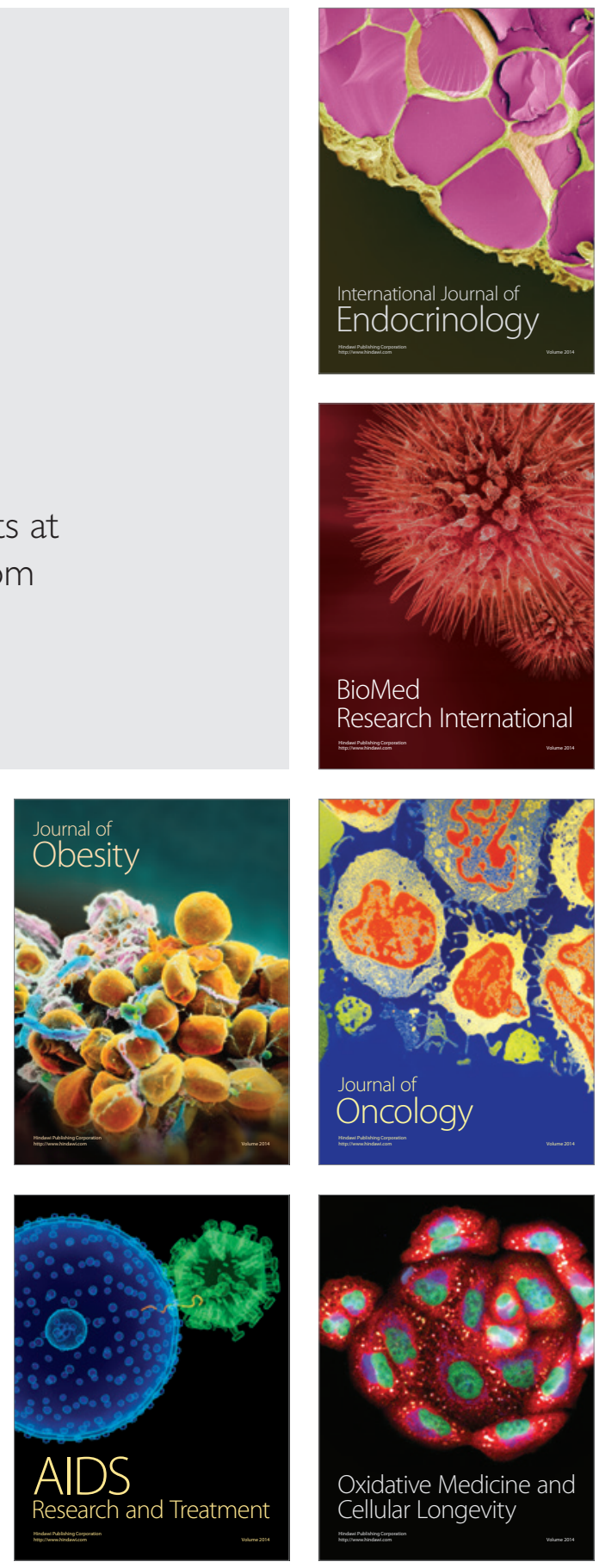